\title{
Review
}

\section{A Critical Evaluation of Wet Biomarkers for Huntington's Disease: Current Status and Ways Forward}

\author{
Edina Silajdžića,* and Maria Björkqvist ${ }^{\mathrm{b}}$ \\ ${ }^{a}$ Division of Cell Matrix Biology and Regenerative Medicine, School of Biological Sciences, \\ Faculty of Biology, Medicine and Health, University of Manchester, Manchester, UK \\ ${ }^{\mathrm{b}}$ Department of Experimental Medical Science, Brain Disease Biomarker Unit, Wallenberg \\ Neuroscience Center, Lund University, Lund, Sweden
}

\begin{abstract}
There is an unmet clinical need for objective biomarkers to monitor disease progression and treatment response in Huntington's disease (HD). The aim of this review is, therefore, to provide practical advice for biomarker discovery and to summarise studies on biofluid markers for HD. A PubMed search was performed to review literature with regard to candidate saliva, urine, blood and cerebrospinal fluid biomarkers for HD. Information has been organised into tables to allow a pragmatic approach to the discussion of the evidence and generation of practical recommendations for future studies. Many of the markers published converge on metabolic and inflammatory pathways, although changes in other analytes representing antioxidant and growth factor pathways have also been found. The most promising markers reflect neuronal and glial degeneration, particularly neurofilament light chain. International collaboration to standardise assays and study protocols, as well as to recruit sufficiently large cohorts, will facilitate future biomarker discovery and development.
\end{abstract}

Keywords: Huntington's disease, biomarker, blood, plasma, serum, cerebrospinal fluid, urine, saliva

\section{INTRODUCTION}

Huntington's disease (HD) is an inherited neurodegenerative disorder caused by a CAG triplet repeat expansion in the gene encoding huntingtin [1]. HD is clinically characterised by a variable phenotypic expression of motor, cognitive and psychiatric symptoms [2], with typical age-at-onset in the thirties or forties [3] and a slow disease progression [4]. The age-at-onset, severity and duration of disease are very

\footnotetext{
${ }^{*}$ Correspondence to: Edina Silajdžić, Division of Cell Matrix Biology and Regenerative Medicine, School of Biological Sciences, Faculty of Biology, Medicine and Health, University of Manchester, Manchester, UK. E-mail: Edina.Silajdzic@manche ster.ac.uk.
}

variable and depend on CAG repeat length as well as other genetic and environmental factors [3]. Although many clinical features of HD can be ascribed to the dysfunction and death of neurons, the causative mutant huntingtin protein is expressed ubiquitously and evidence is emerging of a role for non-neuronal tissues in the pathogenesis of HD [5-7].

\section{Biomarker definition}

The term biomarker is defined as "a characteristic that is objectively measured and evaluated as an indicator of normal biological processes, pathogenic processes, or pharmacologic responses to a therapeutic intervention" [8]. Therefore, a biomarker can be 
Table 1

Biomarker categories and definitions

\begin{tabular}{ll}
\hline Biomarker category & Definition \\
\hline Screening & Biomarkers for early detection of disease. \\
Diagnostic & Biomarkers for identification of a disorder. \\
Staging & Biomarkers for identification of a particular disease stage. \\
Prognostic & Biomarkers for giving an indication of the likely progression of a disease irrespective of \\
& treatment. \\
Predictive & Biomarkers as indicators of patients who are likely to respond to a particular treatment. \\
Target engagement & Biomarkers that indicate fraction of target binding sites occupied by a drug. \\
Pharmacodynamic & Biomarkers as indicators of interaction between a drug and a target, including both \\
& therapeutic and adverse effects, to assess whether the downstream pathway or biological \\
process regulated by a drug target is perturbed upon drug administration.
\end{tabular}

related to the disease itself or to a treatment effect. Various biomarker categories are defined in Table 1 (based on BEST (Biomarkers, EndpointS, and other Tools) Resource [9]). An ideal disease biomarker should be closely linked to pathophysiology, reliable, accurate, sensitive, specific, reproducible, inexpensive, non-invasive and acceptable for the patient [10].

\section{Huntington's disease biomarkers: Unmet needs}

At present there are no effective treatments in clinical practice that will prevent the disease, halt its progression or delay its onset [11-13], but as the future holds promise for disease modifying strategies [14], there is a need for reliably assessable disease progression biomarkers, as well as markers to evaluate therapeutic interventions. As a chronic progressive disorder, $\mathrm{HD}$ has a premanifest phase during which no motor signs are present, but the underlying pathological processes are ongoing $[15,16]$. The possibility of genetic testing in HD opens up the possibility of evaluating disease-modifying treatments already in the premanifest phase. Thus, biomarkers that reflect underlying disease processes or progression are needed to monitor changes in clinically asymptomatic individuals [17]. Biomarkers providing an objective measurement for the assessment of HD severity would also be valuable in the clinical care of existing HD patients and might prove particularly useful in a clinical trial context, potentially serving as surrogate endpoints. In 2004, the U.S. Food and Drug Administration (FDA) emphasised the importance of biomarkers in improving drug development efficiency [18] and continues to promote research on potential new biomarkers to use as surrogates in future trials [19]. Since then, there has been an increase in the use of biomarkers in all phases of drug development. Impaired proteasome activity [20], transcriptional dysregulation [21], oxidative stress [22], mitochondrial and metabolic dysfunction [23], neuroinflammation [24, 25], and microglial activation [26-28] have been shown to play important roles in the pathogenesis of $\mathrm{HD}$ and many biomarker studies have been undertaken that reflect these processes (clinical, imaging and biofluid). Although much data has been generated, the road to clinical application is long and validation of the intended use in independent cohorts is challenging. To help identify the most promising candidate biomarkers, we reviewed "wet biomarker" literature in HD published to date. Here, we are defining a "wet biomarker" as a potential biomarker that is objectively measured in a bodily fluid. We have limited our focus to studies in blood, urine, saliva and CSF and have excluded DNA, RNA and microRNA studies. While these studies are also of great interest, they require a different set of criteria from markers discussed here and are beyond the scope of this review. We have built our discussion around a table giving an overview of wet biomarker studies to date. The supplementary table is an unbiased summary including all studies regardless of methodology and reproducibility, describing the markers evaluated, the number of subjects, disease stage and the main finding of the study. At the outset, our intention was to also include a table showing "validated" wet biomarkers that have been consistently reproduced and validated longitudinally; however, only one of the markers reviewed here met these criteria. None of the studies to date have yielded biomarkers for accurately predicting either age at onset or disease progression for HD. Since the first step towards clinical implementation of a newly discovered biomarker is independent replication, we focus on biomarkers that have been validated in at 
least two independent cohorts and we discuss recent data challenging earlier findings. The goal of this critical review is to highlight the most promising markers for future validation studies and to help investigators design future biomarker studies in HD.

\section{METHODS}

A literature search was performed using the Pubmed electronic database up to the 17th of February 2018 employing the following search terms: "Huntington's disease" or "Huntington disease" and "saliva" or "urine" or "blood" or "plasma" or "serum" or "cerebrospinal fluid" or "CSF" and filtering on English language articles. The search yielded 1351 results ${ }^{1}$. Abstracts were screened for relevance and studies assessing biofluid markers in HD were included in the final list, with the exception of hormone function tests since they are measuring the response to an activating stimulus. In addition, we checked reference lists published in review articles and other scientific reports and thus added additional references to the final list that were considered relevant and not retrieved by the PubMed research. The final list contained 160 studies.

\section{REVIEW OF WET BIOMARKER LITERATURE IN HUNTINGTON'S DISEASE}

Supplementary Table 1 is an unbiased summary of wet biomarker literature in HD, showing analytes that were tested in biofluids as potential biomarkers for HD. Supplementary Table 1 contains the following information: PMID, analyte, type of sample (e.g., CSF), number of subjects the data is based on (and whether the controls are matched), significant correlations with clinical measures (or lack of correlation), method (technical platform, time of sample collection, fed/fasted status, and whether the subjects are medication-free), first author, last author and year of publication. Out of these, $24 \%$ were tested only once and found to be significantly different in HD compared to control, and $34 \%$ were tested only once with no significant difference reported. Of the analytes tested, $22 \%$ were tested on more than one occasion and were found to be similar in HD and control cohorts (Table 9). We considered all relevant

\footnotetext{
${ }^{1}$ Although effort was taken to include all relevant publications, limitations of the search engine may have resulted in a minority of relevant papers being overlooked.
}

biomarker studies, and divided the biomarkers into several categories reflecting the strength of evidence; this classification was primarily based on the number of replication or validation cohorts and the number of studies that confirmed the findings (described in the "codes" tab of the supplementary Table). The markers that are most promising based on this selection criteria are subdivided into traditional functional classifications in Tables 2 to 7 and are discussed below.

\section{Immune markers (Table 2)}

Both innate and adaptive immune systems have been suggested to play a role in HD pathology [29] and a number of studies have highlighted the existence of a peripheral immune response in HD patients. An unbiased proteomics screen of HD plasma identified immune proteins that are elevated in HD compared to healthy controls [30], including proinflammatory cytokine IL-6, acute-phase protein alpha-2-macroglobulin, complement factors and a complement inhibitor clusterin (Table 2). The authors hypothesised that IL- 6 induces the release of acutephase proteins and this in turn leads to the activation of the complement cascade and modulating factors such as clusterin [30]. A follow-up study demonstrated that immune changes are apparent even during the preclinical stage of HD [24] with IL-6 increased even in premanifest subjects, presenting the possibility that inflammatory markers in plasma can be used to track HD. The findings of increased IL-6 levels in HD plasma were replicated in three independent studies [31-33], however, no change has also been reported [34-36] (Table 2).

Acute-phase proteins alpha-1 antitrypsin [37], alpha-2-macroglobulin [30, 37] and C-reactive protein (CRP) [31, 34, 37-40] have been investigated as potential biomarkers in HD. One study found decreased levels of CRP in one HD cohort and no significant difference in another [37], whereas several other studies reported raised CRP levels in HD subjects [31, 34, 38, 40] (Table 2). Increased CRP level may reflect an acute-phase response due to mutant huntingtin expression in HD. However, as HD mutation carriers that use antipsychotics are prone to develop an acute phase response [39], it is possible that the CRP increase reflects the use of antipsychotics by HD subjects studied. It still remains to be confirmed whether CRP is indeed increased in HD and if yes, whether this increase tracks with disease progression. 
Table 2

Immune markers in HD compared to control

\begin{tabular}{lccc}
\hline Analyte & Result & Correlates with ... & Reference \\
\hline$\alpha 1-$ Microglobulin, Urine & $\uparrow$ & & {$[274]$} \\
sTNF-R & $\uparrow$ & & {$[41,42]$} \\
Clusterin & $\uparrow$ & {$[30]$} \\
CRP & $\uparrow$ & & {$[37]$} \\
& $\uparrow$ & & {$[31,40]$} \\
IL-6 & $\downarrow$ & Independence [32] & {$[37]$} \\
& $\uparrow$ & TFC [32] & {$[36-39,41]$} \\
& & Cognition [33] & \\
Neopterin & $=$ & Microglial activation [35] & {$[34-36]$} \\
sIL-2R & $\uparrow$ & Cognition [41] & {$[40-43]$} \\
\hline Any & $\uparrow$ & & {$[41,42]$} \\
\hline
\end{tabular}

Analytes were measured in blood, unless otherwise specified. Abbreviations: 55-kDa-type soluble tumour necrosis factor receptor (sTNF-R). C-reactive protein (CRP). Interleukin-6 (IL-6). Soluble interleukin-2-receptor (sIL-2R).

Neopterin is synthesised by macrophages following interferon gamma stimulation and is a marker of cellular immune system activation. Several studies have consistently reported increased neopterin levels in late stages of HD [40-43]; however, no followup studies in early stages of the disease have been performed.

\section{Metabolic markers (Table 3)}

It is reported that there is a negative energy balance in HD [44] and many of the peripheral manifestations of HD, such as weight loss [45] and muscle wasting are indicative of metabolic alterations. This is reflected in the fact that many of the analytes tested as potential biomarkers for HD are metabolites (Table 3). Advances in metabolomics provide the opportunity to exploit this catabolic phenotype to discover novel biomarkers for HD. An untargeted metabolomic study using gas chromatography and mass spectrometry to analyse serum from control subjects, premanifest and early stage HD found metabolic alterations associated with a catabolic phenotype [46], thus confirming longstanding reports that catabolic changes in amino acid metabolism occur before onset of symptoms [47]. Levels of branched chain amino acids (valine, leucine and isoleucine) have been consistently reported to be correlated with weight loss, disease progression and abnormal triplet repeat expansion [36, 46-55] (Table 3). However, there are also a number of studies that report no change in branched chain amino acids [38, 47, 56-58].

Many studies have investigated markers of lipid metabolism, in particular, cholesterol metabolism in HD. Most studies have shown no alteration in peripheral levels of total cholesterol, HDLcholesterol and LDL-cholesterol [57, 59-64], with the exception of Wang et al. [34] that showed a reduction of all three analytes in premanifest as well as manifest HD subjects. The major brain cholesterol metabolite 24(S) hydroxycholesterol (24OHC) reduction has consistently been observed in plasma of individuals with $\mathrm{HD}[59,65,66]$ and was paralleled by the reduction of caudate volume, suggesting that the reduction of $24 \mathrm{OHC}$ may reflect progressive neuronal loss [59] (Table 3). Additionally, HD patients' plasma also showed reduced levels of cholesterol precursors lanosterol and lathosterol, and of the bile acid precursor 27-hydroxycholesterol [65]. Future studies need to follow subjects longitudinally to examine the rate of change of metabolic markers as the disease progresses.

\section{Endocrine markers (Table 4)}

In the tuberal nucleus of the lateral hypothalamus of HD patients there is progressive neuronal death that could have an impact on the function of most of the pituitary axes [67-72]. Consequently, numerous neuroendocrine studies have been carried out in $\mathrm{HD}$, although sometimes with conflicting results (Table 4).

\section{Melatonin}

One neuroendocrine marker that shows great promise is melatonin (Table 4). Three studies that analysed 24-hour profiles of melatonin secretion have reported melatonin alterations in HD subjects 
Table 3

Metabolic markers in HD compared to control

\begin{tabular}{|c|c|c|c|}
\hline Analyte & Result & Correlates with ... & Reference \\
\hline $24 \mathrm{OHC}$ & $\downarrow$ & $\begin{array}{c}\text { TMS }[65,66] \\
\text { Cognition [66] } \\
\text { Striatal volume [66] } \\
\text { Caudate volume [59] }\end{array}$ & {$[59,65,66]$} \\
\hline $5-\mathrm{HT}$ & $\begin{array}{l}\uparrow \\
\downarrow \\
=\end{array}$ & & $\begin{array}{c}{[275]} \\
{[55,107]} \\
{[43]}\end{array}$ \\
\hline ApoA4, CSF & $\uparrow$ & & {$[117,276]$} \\
\hline Arginine & $\begin{array}{l}\uparrow \\
=\end{array}$ & & $\begin{array}{c}{[57,58]} \\
{[38,47,55-57]}\end{array}$ \\
\hline Cholesterol, total & $\begin{array}{l}\downarrow \\
=\end{array}$ & $\begin{array}{l}\text { Psychosis [277] } \\
\text { Cognition [278] }\end{array}$ & $\begin{array}{c}{[34,65,277]} \\
{[57,59-64,102,106,278,279]}\end{array}$ \\
\hline Citrulline & $\begin{array}{l}\uparrow \\
=\end{array}$ & Duration [280] & $\begin{array}{l}{[280,281]} \\
{[38,55-57]}\end{array}$ \\
\hline Homocarnosine & $\downarrow$ & & {$[282,283]$} \\
\hline Homovanillic acid & $\uparrow$ & $\begin{array}{l}\text { Severity [284] } \\
\text { TFC [284] }\end{array}$ & {$[107,284]$} \\
\hline Homovanillic acid, CSF & $\begin{array}{l}\downarrow \\
=\end{array}$ & & $\begin{array}{c}{[285,286]} \\
{[79,287]}\end{array}$ \\
\hline Isoleucine & $\downarrow$ & $\begin{array}{l}\text { CAG [36] } \\
\text { UHDRS [36] }\end{array}$ & {$[36,47,48,55]$} \\
\hline & $=$ & & {$[56,57]$} \\
\hline Leucine & $\begin{array}{l}\uparrow \\
\downarrow\end{array}$ & $\begin{array}{l}\text { CAG }[36,48] \\
\text { UHDRS [36] }\end{array}$ & $\begin{array}{c}{[46]} \\
{[36,48]}\end{array}$ \\
\hline Phenylalanine & $\begin{array}{l}= \\
\uparrow P \\
=\end{array}$ & & $\begin{array}{c}{[38,47,55-57]} \\
{[57]} \\
{[55,56,58,288]}\end{array}$ \\
\hline Phosphoethanolamine, CSF & $\downarrow$ & & {$[282,289]$} \\
\hline PC.ae.C36.0 & $\downarrow$ & Severity [58] & {$[55,58]$} \\
\hline Tryptophan & $\downarrow$ & $\begin{array}{c}\text { Cognition }[41,42] \\
\text { Stage [108] } \\
\text { CAG [108] }\end{array}$ & {$[41,42,108]$} \\
\hline & $=$ & & {$[40,43,55-58,107,279]$} \\
\hline Tyrosine & $\begin{array}{l}\uparrow P \\
=\end{array}$ & & $\begin{array}{c}{[57,107]} \\
{[47,55-58]}\end{array}$ \\
\hline Valine & $\begin{array}{c}\uparrow \mathrm{P} \\
\downarrow\end{array}$ & $\begin{array}{l}\text { CAG }[36,48] \\
\text { UHDRS [36] }\end{array}$ & $\begin{array}{c}{[57]} \\
{[36,46,48,55]}\end{array}$ \\
\hline & $=$ & & {$[38,47,56-58]$} \\
\hline
\end{tabular}

Analytes were measured in blood, unless otherwise specified. Abbreviations: 24S-hydroxycholesterol (24OHC). 3-hydroxyanthranilic acid (3HAA). 5-hydroxytryptamine / Serotonin (5-HT). Apolipoprotein A4 (ApoA4). Phosphatidylcholine acyl-alkyl C36:0 (PC.ae.C36.0). Premanifest HD (P).

[73-75]. One study found a delay in evening rise of melatonin in HD [74], whereas another found reduced melatonin levels and reported that the evening rise of melatonin was significantly more temporally spread in both premanifest and stage II/III HD subjects [75]. A study measuring melatonin at a single time point (in the morning after an overnight fast) in advanced HD patients found no difference compared with controls [43]. In the three studies measuring 24-hour levels of melatonin, morning melatonin levels were similar in controls and HD subjects [73-75], highlighting the fact that single measures cannot reflect the dynamic range of melatonin over 24 hours. Thus, when it comes to measuring levels of markers that have a circadian rhythmicity it may be necessary to examine the 24-hour profile in the first instance to see if the circadian rhythm is disrupted and to determine at what time of day the marker is most informative. As such, studies measuring hormones at only one time-point may not provide enough information.

\section{Cortisol}

Abnormal hypothalamic-pituitary-adrenal (HPA) axis function has been reported in HD mouse models and in HD patients [76-81]. HPA axis hyperactivity has been reported in early disease stage, primar- 
Table 4

Endocrine markers in HD compared to control

\begin{tabular}{|c|c|c|c|}
\hline Analyte & Result & Correlates with ... & Reference \\
\hline \multirow[t]{2}{*}{ Cortisol } & $\uparrow$ & & {$[73,76,78,80]$} \\
\hline & $=$ & & {$[36,38,57,81,84,85]$} \\
\hline \multirow[t]{3}{*}{ Cortisol, saliva } & $\uparrow \mathrm{P}$ & Depression (P\&E) [82] & {$[82,83]$} \\
\hline & $=$ & Cognition [290] & {$[86,93,290]$} \\
\hline & & Depression [86] & \\
\hline \multirow[t]{5}{*}{ Ghrelin } & $\uparrow$ & & {$[34,36,57,97]$} \\
\hline & $=$ & CAG [161] & {$[57,63,161]$} \\
\hline & & TFC $[161]$ & \\
\hline & & TMS [161] & \\
\hline & & Independence [161] & \\
\hline \multirow[t]{8}{*}{$\mathrm{GH}$} & $\uparrow$ & TFC [81] & {$[61,81,93]$} \\
\hline & & TMS [81] & \\
\hline & & Independence [81] & \\
\hline & $\downarrow$ & & {$[34]$} \\
\hline & $=$ & TFC [161] & {$[57,84,97,161,291-294]$} \\
\hline & & TMS [161] & \\
\hline & & Independence [161] & \\
\hline & & Cognition $\left(\sigma^{7}\right)$ [295] & [295] \\
\hline \multirow[t]{6}{*}{ IGF-1 } & $\uparrow$ & TFC [81] & [81] \\
\hline & & TMS [81] & \\
\hline & & Independence [81] & \\
\hline & $\downarrow$ & UHDRS [36] & {$[36,61]$} \\
\hline & $=$ & & {$[84,97,161]$} \\
\hline & & Cognition $[295,296]$ & {$[295,296]$} \\
\hline Leptin & $\downarrow$ & & {$[36,97]$} \\
\hline \multirow[t]{4}{*}{ Leptin } & $=$ & CAG [297] & {$[34,57,63,297]$} \\
\hline & & TFC [297] & \\
\hline & & TMS [297] & \\
\hline & & Independence [297] & \\
\hline \multirow[t]{2}{*}{ Melatonin, 24-hour } & $\downarrow$ & TFC [74] & [73-75] \\
\hline & Disrupted evening rise & TMS [74] & \\
\hline Melatonin, am & $=$ & & [43] \\
\hline Transthyretin, CSF & $\downarrow$ & & {$[117,298]$} \\
\hline
\end{tabular}

Table 5

Oxidative stress markers in HD compared to control

\begin{tabular}{lccc}
\hline Analyte & Result & Correlates with ... & Reference \\
\hline 3HAA & $\downarrow$ & & {$[40,107]$} \\
Cu/Zn-SOD & $=$ & & {$[108,279]$} \\
Ferritin & $\uparrow$ & {$[62,64]$} \\
GSH & $\downarrow$ & & {$[105]$} \\
& $\downarrow$ & Caudate atrophy [106] & {$[299,300]$} \\
Kynurenic acid, CSF & $=$ & & {$[102,105]$} \\
Kynurenine & $\downarrow$ & & {$[106]$} \\
& $\uparrow$ & & {$[301,302]$} \\
Lipid peroxidation & $\downarrow$ & TMS [103] & {$[40,42]$} \\
& $=$ & Independence $[103]$ & {$[107,279]$} \\
& $\uparrow$ & & {$[41,55,108]$} \\
& & & {$[108,274]$} \\
\hline
\end{tabular}

Analytes were measured in blood, unless otherwise specified. Abbreviation: 3-Hydroxyanthranilic acid (3HAA). Cu/Zn-superoxide dismutase (Cu/Zn-SOD). Reduced glutathione (GSH)/ L- $\gamma$-glutamyl-Lcysteinylglycine. 
Table 6

Neuropeptide, glial and axonal degeneration markers in HD compared to control

\begin{tabular}{|c|c|c|c|}
\hline Analyte & Result & Correlates with ... & Reference \\
\hline \multirow[t]{2}{*}{ GABA, CSF } & $\downarrow$ & & [303-305] \\
\hline & $=$ & & {$[304,306,307]$} \\
\hline NGF & $\downarrow$ & Severity [308] & {$[308,309]$} \\
\hline \multirow[t]{11}{*}{ NF-L } & $\uparrow$ & Burden [112] & [112] \\
\hline & & Putamen volume $[112,115]$ & \\
\hline & & Caudate volume [115] & \\
\hline & & Striatal volume [112] & \\
\hline & & White matter volume $[112,115]$ & \\
\hline & & Grey matter volume $[112,115]$ & \\
\hline & & Lateral ventricle volume [112] & \\
\hline & & Cognition [112] & \\
\hline & & TFC [112] & \\
\hline & & TMS [112] & \\
\hline & & Onset [112] & \\
\hline \multirow[t]{5}{*}{ NF-L, CSF } & $\uparrow$ & Burden [111] & [109-114] \\
\hline & & Onset [113] & \\
\hline & & TFC $[109,113]$ & \\
\hline & & TMS [111-113], & \\
\hline & & Cognition $[111,114]$ & \\
\hline \multirow[t]{4}{*}{ Total tau, CSF } & $\uparrow$ & Burden [118] & {$[110,113,114,116,118]$} \\
\hline & & TFC $[113,118]$ & \\
\hline & & TMS $[113,118]$ & \\
\hline & & Cognition $[114,118]$ & \\
\hline NSE & $\uparrow$ & & {$[62,64]$} \\
\hline Total tau, CSF & $=$ & & {$[111]$} \\
\hline \multirow[t]{4}{*}{ YKL-40, CSF } & $\uparrow$ & Burden [111] & {$[110,111,117]$} \\
\hline & & Stage [110] & \\
\hline & & TFC [110] & \\
\hline & & TMS [110] & \\
\hline
\end{tabular}

Abbreviations: $\gamma$-aminobutyric acid (GABA). Chitinase-3-like-protein 1 (YKL-40). Nerve growth factor (NGF). Neurofilament light subunit (NF-L). Neuron-specific enolase (NSE).

Table 7

Mutant huntingtin in HD compared to control

\begin{tabular}{lccc}
\hline Analyte & Result & Correlates with ... & Reference \\
\hline mtHTT, CSF & $\uparrow$ & Burden $[114,119]$ & {$[114,119]$} \\
& & Onset $[114,119]$ & \\
& TMS [114, 119] & \\
& & Cognition $[114,119]$ \\
\hline
\end{tabular}

Abbreviations: Mutant huntingtin (mtHTT).

ily in the morning and early afternoon period [76] and elevated salivary cortisol awakening response (CAR) was found in premanifest HD mutation carriers compared to diagnosed HD individuals [82, 83], but no significant difference was found in overall parameters of HPA axis activity between HD mutation carriers and controls (Table 4). Several other studies also reported no significant difference in cortisol levels between mutation carriers and controls [84-86]; however, in two of these studies morning cortisol levels were higher in premanifest HD subjects compared to symptomatic HD subjects $[84,86]$. It is difficult to directly compare studies that examined HPA axis functioning in HD because various biofluids were used and this can lead to different results. Also the studies were inconsistently adjusted for potential confounders such as smoking status, alcohol consumption, BMI, use of psychotropic medication and presence of depression. In addition, some studies recruited HD family members as the control group [82, 84], and it may be that this control group also has raised cortisol levels compared to the general population [82]. Also, due to circadian rhythmicity in secretion, it may be necessary to examine the 24-hour profile of cortisol in order to fully understand possible alterations in the secretion profile. Taken together these studies seem to indicate that there may be a hyperactivity of the HPA axis in the premanifest stage, as suggested by increased CAR and morning cortisol levels [76, 82-84, 86]. Studies have also shown that approximately $30 \%$ of people with depression have increased cortisol secretion [87-90] and there are some indications that HPA axis alterations may contribute to depressive symptoms during early stages of HD $[82,86]$. Only one of these studies was longitudinal [82], thus more longitudinal 
studies are needed to elucidate whether there is indeed disturbed HPA axis functioning that varies with disease stage and what influence this has on depressive symptoms.

In the future it may be beneficial to also measure cortisol levels in hair because this offers a longer-term view of systemic cortisol exposure than biofluids such as saliva, urine or blood; a centimetre of hair shows the average cortisol over a month [91].

\section{Growth hormone (GH)}

Morning fasting GH levels were reported to be higher in stage I/II HD compared to controls suggesting early dysfunction of the somatotropic axis, and this increased somatotropic activity was associated with disease severity [81]. However, studies analysing GH concentration in HD have yielded conflicting results with three studies reporting an increase in HD patients compared to controls [81, 92, 93] and five studies reporting no significant difference [84, 93-97] (Table 4).

Similarly to cortisol, GH and the tightly linked hormone, IGF-1 (insulin growth factor 1), have multi-organ effects and play major roles in whole body metabolism. It may be necessary to study multiple pathways and endocrine markers in association, to find patterns of changes that track with HD progression.

\section{Oxidative stress markers (Table 5)}

Evidence from studies in both humans and animal models suggests the involvement of energy metabolism dysfunction and oxidative stress in the pathogenesis of HD [98, 99]. It is thought that impairment in the electron transport chain and mitochondrial dysfunction are the major mechanisms involved in increased reactive oxygen species (ROS) production in HD $[100,101]$. It has been reported that HD individuals have an increased level of oxidative stress markers (Table 5) accompanied by a reduction in antioxidant systems compared to healthy subjects $[102,103]$. Several studies have reported enhanced lipid peroxidation in individuals with HD [40, 43, 102-106] (Table 5). Chen et al. [103] detected a correlation between lipid peroxidation products in plasma and degree of severity in patients with $\mathrm{HD}$, while Klepac et al. [105] reported an increase in plasma lipid peroxidation accompanied by reduced glutathione content (Table 5). An increase in $\mathrm{Cu} / \mathrm{Zn}$ superoxide dismutase ( $\mathrm{Cu} / \mathrm{Zn}-\mathrm{SOD})$, an important antioxidant enzyme, has also been reported in HD
[62, 64] (Table 5). In addition, alterations in the kinetics of the kynurenine pathway (a major route of tryptophan catabolism) have been reported in patients with HD [40, 42, 55, 107] (Table 5), although some studies find no alterations [43, 108].

\section{Axonal and glial degeneration markers (Table 6)}

HD is associated with a variety of pathological changes affecting both glial and neuronal brain tissue and these changes may be mirrored in the release of proteins into the CSF, and to lesser extent into the blood. Markers that reflect CNS pathology are needed for disease-modifying agents that target the CNS specifically. Currently, the most promising marker of HD onset and progression is neurofilament light protein (NF-L), a subunit of neurofilaments that make up the neuronal cytoskeleton (Table 6). Four studies have consistently found raised NF-L in CSF of individuals with HD [109-112] and several studies have found CSF NF-L to correlate with clinical measures [109, 111-114]. A recent, longitudinal study has found raised plasma NF-L in HD individuals, a finding confirmed in a separate, cross-sectional cohort [112] (Table 6). This is a very important finding because plasma NF-L levels reflect CNS pathology and may be a useful marker for trials involving CNS-delivery of disease-modifying agents. Importantly, both CSF and plasma NF-L levels have been found to correlate with disease onset in HD $[112,113]$ and brain atrophy [115]. A neuronal damage marker, NSE, is also increased in serum of HD patients [62, 64] (Table 6).

Several other markers of axonal and glial degeneration have been reported to be increased in HD individuals' CSF including myelin basic protein (MBP) [111], total tau (T-tau) [110, 116], and chitinase-3-like-protein 1 (CHI3L1) / YKL-40 [110, $111,117]$. T-tau and YKL-40 have also been found to correlate with clinical measures in some but not all, of the studies [110,113, 114, 118].

These studies suggest that the profile of glialrelated inflammatory CSF biomarkers (such as YKL-40, GFAP, MCP-1, sCD14) and cytoskeletal and myelin markers of neurodegeneration (such as NF-L, T-Tau, P-Tau181, MBL, NSE, UCHL1), and their relation to disease severity should be further investigated.

\section{CSF mutant huntingtin (Table 7)}

Unsurprisingly, mutant huntingtin (mtHTT) has been found to be absent in healthy controls and 
increased in manifest HD CSF compared to premanifest HD CSF [114, 119] (Table 7). It is promising to note that CSF mtHTT levels have shown associations with clinical phenotype $[114,119]$.

\section{CRITICAL EVALUATION OF WET BIOMARKER LITERATURE IN HUNTINGTON'S DISEASE AND FUTURE DIRECTIONS}

Why are studies not reproducible?

When conducting a biomarker study, it is important to consider the future purpose of the biomarker (its context-of-use) [120, 121] (see Fig. 1). For instance, if the purpose of the biomarker is to track disease progression, it should alter with advancing disease.
Therefore, it is important to note that although many of the analytes in Supplementary Table 1 are not useful markers for HD in terms of disease progression, that does not mean that they would not be useful as, for example, pharmacodynamic markers.

This review of published HD biomarker studies to date reveals that very few wet biomarkers have been consistently and reliably reproduced; there are many conflicting studies that could be due to a myriad of variability factors. In biomarker discovery studies, great attention needs to be paid to several aspects of study design, sample collection, sample measurement and data analysis [122-125]. Factors to consider during biomarker discovery are outlined in Fig. 1. Below we discuss potential sources of variability in biomarker studies and suggest considerations for further developments and harmonisation of standard operating procedures (SOPs).

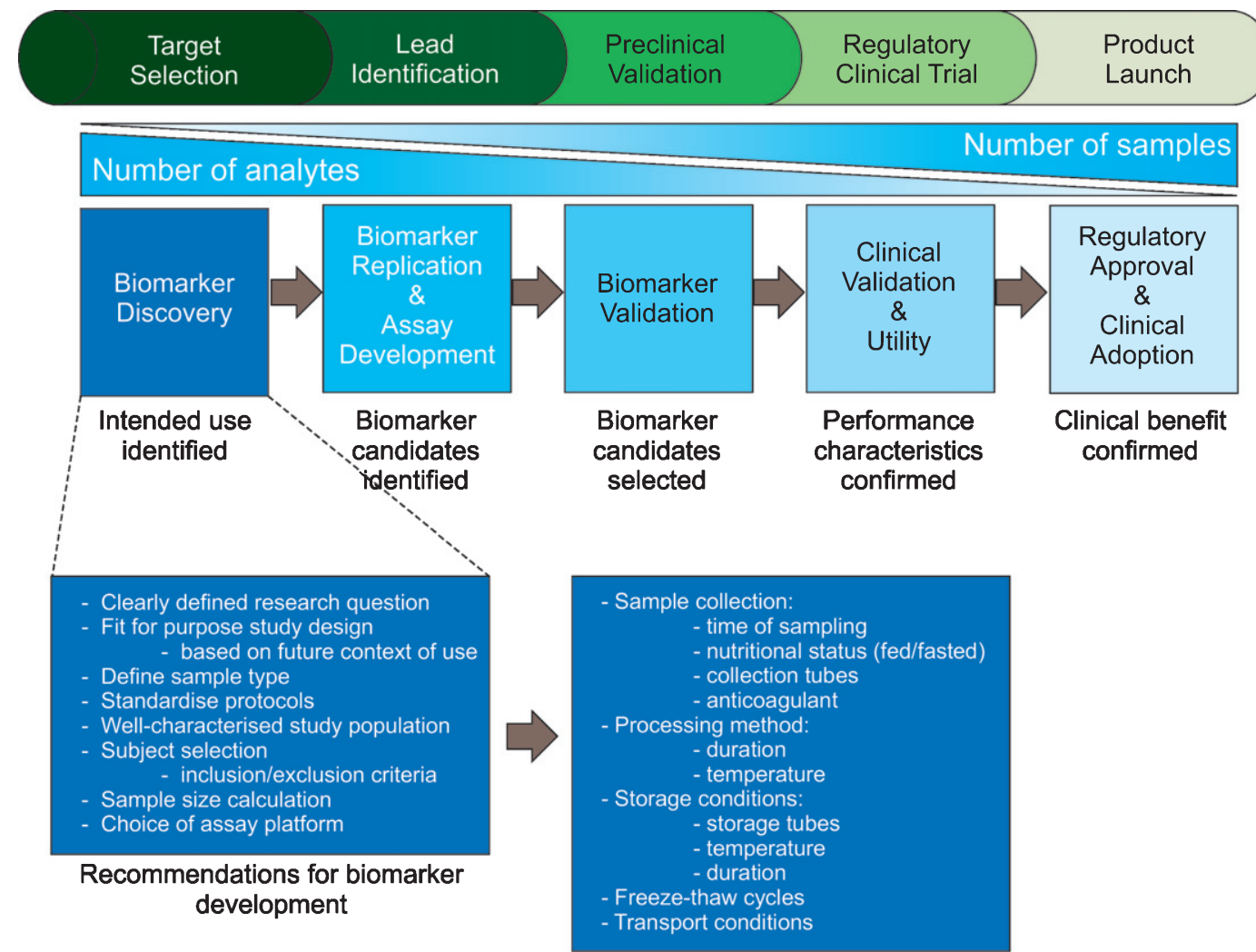

Recommendations for preanalytical standardisation

Fig. 1. Phases of biomarker development and recommendations for biomarker discovery studies. Biomarker development from target selection and biomarker discovery to the product launch of a clinical assay that has been validated in large cohorts is a time-consuming, expensive process. It is, therefore, important that makers put forward for clinical validation are based on solid evidence. Here, we suggest factors to consider during biomarker study design to ensure meaningful data are produced. Adapted from [273]. 


\section{Biological variation}

Within-subject (intra-individual) biological variation is the inherent change in analyte results around a homeostatic setting point within an individual over time [126, 127]. Individual homeostatic setting points are different and this difference between individuals is termed between-subject (interindividual) biological variation [126, 127]. Some analytes have predictable biological rhythms that may cycle daily (e.g. cortisol, GH) [128], monthly (e.g., luteinizing hormone (LH), follicle-stimulating hormone (FSH), progesterone) [129, 130] or seasonally (e.g., vitamin D, cholesterol) [131-133]. With advancing age blood levels of some hormones increase (e.g., cortisol [134, 135], FSH [136], LH [137], noradrenaline [138]); decrease (e.g., melatonin [139], aldosterone [140, 141], GH [142], oestrogen in women [143], prolactin in women [144]); or change only slightly (e.g., adrenaline [145], insulin [146], thyroid hormone T4 [147]). In addition, some hormones are metabolised more slowly with age [147].

Some analytes can even be affected by activity levels; for instance, exercise prior to sample collection can result in higher cytokine and myokine levels in plasma [148]. Many HD individuals require medication for their symptoms and it is often difficult to get a medication-free cohort. Medication can influence analyte levels, e.g., $[149,150]$, and thus needs to be taken into consideration when interpreting results.

A large biological variability requires studies with larger subject cohorts. Lessons learned from cardiovascular biomarker research illustrate the importance of effect size; the prognostic effect was shown to be significantly stronger in datasets from observational studies than in datasets from randomised controlled trials [151]. As can be observed from Supplementary Table 1, many HD biomarkers studies to date have used less than 20 subjects per group, making it likely that the studies are underpowered.

Biological variation due to factors such as age, gender, diet, ethnicity, smoking, alcohol consumption, or medication may, at least in part, explain the contradicting results seen in different studies [152]. For example, for haemoglobin, the main sources of between-subject variation is clinical indication, but following that gender, age and nationality greatly influence variation [153], whereas CRP is not only affected by age, but also, to a large extent, gender $[154,155]$. Confounding factors may be controlled for by selecting the most appropriate time of day, month or year for sample collection or may be taken into consideration in the interpretation of results. A study examining classification of control subjects from Alzheimer's disease patients showed that removal of causes of variability such as age and gender can significantly improve classification accuracy [156]. Therefore, it is paramount to have a well-characterised cohort and a balanced design that minimises the number of uncontrolled covariates such as age and sex. If they are not matched, confounding factors should at the very least be controlled for in the statistical analyses [157, 158].

\section{Study design: Considering preanalytical variables}

Preanalytical variables such as time of day that the sample is obtained, anticoagulant choice, feeding state and acute stress of the patient, and method and duration of sample storage can influence reported analyte levels and should be documented [159, 160]. Below we discuss how pre-analytical variables contribute to variation in biomarker studies.

\section{Patient selection: Disease stage}

The major potential criticism of the value of many of the markers we discuss here for HD is that they are non-specific or variable from day to day or that they could be epiphenomena caused by a general illness state. Certainly nutritional, metabolic and infective pathology are likely to contribute to marker variability with advancing HD. Studies performed to date are often not comparable due to heterogeneity in patient cohorts in terms of disease stage; some studies focus on specific disease stages, e.g., [161], whereas others group all the manifest HD subjects from early to late stage, e.g., [81]. Analyte alterations that are seen before the onset of overt clinical features should be pursued as there may be a direct relationship to pathogenesis with the potential to inform the search for disease markers [17].

\section{Time of sampling}

Secretion of some analytes such as cytokines [162] and homocysteine [163] as well as hormones, such as ACTH, cortisol and growth hormone, shows circadian rhythmicity $[164,165]$. Time of sampling might, therefore, affect results, especially if the expected alterations are subtle. Also, for some markers, it is possible that no difference is observed if only one timepoint is evaluated, but it might be the pattern of secretion that is altered. For instance, in premani- 
fest HD subjects, there is no significant difference in mean levels of melatonin over 24 hours but there is a disruption in circadian rhythmicity [75]. Therefore, the ideal time of sampling needs to be determined for each marker and thereafter, the time of day that samples are collected should be standardised to allow direct comparisons between studies [166].

\section{Fed or fasted state}

Levels of hormones such as growth hormone [167], insulin [168] and leptin [169] can be influenced by the feeding status and thus, levels may vary depending on whether the subject had just had a meal or if the samples were taken after an overnight fast. Also, feeding status can affect cytokine production and action [170, 171]. Circulating CRP and IL-6 are elevated following a high-fat meal, while TNF-alpha levels decrease [172]. In addition, the supplementation of particular antioxidants such as glutathione, vitamins $\mathrm{E}$ and $\mathrm{C}$ can attenuate the feeding-induced rise in plasma cytokines $[173,174]$. To avoid nutritional interference, studies should firstly determine whether nutritional status affects the analyte in question and secondly, need to be consistent in whether fed or fasted samples are used [175].

\section{Blood collection tubes and specimen processing}

For many blood biomarkers, either serum or plasma can be used [176, 177], however, for some biomarkers it is important to use a specific matrix and anticoagulant [178]. For example, studies demonstrate that plasma is intrinsically more stable than serum and therefore, more useful for protein analyses in biomarker studies [179, 180].

There is a wide selection of blood collection tubes available, and analyte levels can vary according to the type of collection tube used [181-186]. Blood collection devices and insufficient filling of blood collection tubes are another source of preanalytical error [187]. Care needs to be taken to ensure that the collection tubes are appropriate for analytes to be tested and that the type of collection tube is consistent throughout the study, especially if it is a multi-centre study.

It is also vital to standardise the pre-processing duration because the length of time that the samples are kept at room temperature after collection and before processing can alter analyte levels [188-190].

\section{Sample storage and analyte stability}

Both in vivo and in vitro analyte stability needs to be considered in biomarker studies because data obtained from stored specimens of an unstable biomarker may not produce any meaningful results [191]. Some potentially useful markers have very short half-lives and cannot reliably be measured and many proteins are unstable in serum even at $-80^{\circ} \mathrm{C}$ $[189,192]$. It is, therefore, important that the storage temperature of samples is appropriate for the analyte tested [193]. Thus, biomarker studies should standardise and document the temperature and the duration of sample storage [194].

Splitting samples into multiple aliquots is recommended for analytes that have a freeze-thaw instability, e.g., cytokines [195]. In addition, it is important that the type of storage tube is appropriate [196] and that tubes are filled sufficiently to avoid oxidation.

\section{Multi-centre studies}

As highlighted above, differences in sample preparation can influence absolute analyte levels. Therefore, to ensure that preanalytical variability is kept to a minimum in multi-centre studies, SOPs for collection, processing, storage and transport of samples should be created, formalised, and strictly adhered to [194, 197, 198]. The importance of standardising pre-analytical variables was clearly demonstrated in a study of BDNF in serum and plasma [189] where the authors found many issues concerning BDNF detection that make reliable measurement difficult. The length of time between blood collection and plasma preparation affected BDNF levels, possibly due to BDNF release from platelets [199], suggesting that more robust and standardised procedures are required for plasma preparation. Also, BDNF was unstable in serum prepared following standardised protocols and stored at $-80^{\circ} \mathrm{C}$, but was stable in plasma. The authors emphasise that intra-group variability can be a major problem, especially because BDNF levels are affected by a number of individual factors such as exercise, stress, age, weight and gender [200-203] and preanalytical variables, including: fasting or fed condition, types of blood collection tubes (EDTA or heparintreated) [204], duration and conditions of sample storage [192].

When using samples from different clinical centres, all diagnostic groups (including controls) need to be obtained from each clinical centre to be able to investigate potential variations in biomarker levels between different clinical sites. TRACK-HD [205] is a good example of a multi-centre study where the same stringent sampling procedure has been used at 
different sites. It will be interesting to see if markers evaluated in this sample cohort provide potential future biomarkers for HD progression. The EUROHD network [206] is coordinating Clinical Centres within Europe with the aim of applying standardised protocols in response to criteria identified by tissue banking specialists and encourages sample deposition in a single bank (for HD studies: BioRep s.r.l. in Milan, [207]).

\section{Analytical variables}

\section{Assay imprecision}

The biochemistry of a biomarker needs to be understood in order to target the appropriate form of the biomarker that appears in biofluids. For instance, after production many proteins undergo post translational modifications, such as phosphorylation and glycosylation [208] and the analytical specificity of antibodies to these modifications determines the specificity of the corresponding assay for the biomarker.

For an assay to be a reliable tool, reproducibility and variability are of major importance. Assay variability is affected by many different factors, including within-assay run variability (between duplicate samples), within-laboratory longitudinal variability, between-laboratory variability, and within- and between-assay kit lot variability [209]. Analytical imprecision should be assessed and taken into account when evaluating biomarker data because is important to determine if a particular result is a true result or the result of variance within the measurement procedure itself $[210,211]$.

For novel biomarkers there are usually no standardised or harmonised assays available and manufacturers of diagnostic tests often use different reagents. This is especially problematic in the case of immunoassays, as the performance of a test is dependent on the quality and location of the epitope that the antibody is selected against [212, 213]. As such, absolute results cannot be compared in studies that use different methods and this can lead to contrasting results. Given the lack of assay standardisation, it is important for each laboratory to ensure stability in its measurements [214] and to consider assay variability and limits of quantitation when interpreting biomarker data. Recommendations for technical validation, standardised protocols for assay evaluation and reporting templates are available $[215,216]$.
Table 8

Validation of biomarker research for use in medicine

\begin{tabular}{lc}
\hline Analytic validity & $\begin{array}{c}\text { Do different labs, techniques, and } \\
\text { platforms measure the same thing? } \\
\text { Can other scientists access the data and } \\
\text { protocols, repeat the analyses, and get } \\
\text { the same results? }\end{array}$ \\
Replication & $\begin{array}{c}\text { Do many different data sets and their } \\
\text { combination (meta-analysis) get } \\
\text { consistent results? }\end{array}$ \\
External validation & $\begin{array}{c}\text { Do different data sets by different teams, } \\
\text { preferably prospectively and with larger } \\
\text { cohorts, get consistent results? }\end{array}$ \\
Clinical validity & $\begin{array}{c}\text { Does the discovered information predict } \\
\text { clinical outcomes? }\end{array}$ \\
Clinical utility & $\begin{array}{c}\text { Does the use of the discovered information } \\
\text { improve clinical outcomes? }\end{array}$ \\
\hline
\end{tabular}

Adapted from [217]

\section{Importance of replication and validation}

As can be seen in Supplementary Table 1, many biomarkers have been proposed for HD, however, most have been evaluated in only a few studies. For a biomarker to be recognised, there is a need for validation and independent replication [217, 218]. Validation generally refers to a replication experiment performed by the same research laboratory with a different technology or a different sample cohort, whereas an independent replication of results is usually performed by an outside laboratory (Table 8). Validation for the intended purpose, at both technical and clinical levels, is essential in biomarker studies. The best biological validation of a biomarker is via its clinical correlations and clinical relevance, showing consistent data in cross-sectional and longitudinal studies and repeatability across different clinical studies.

The need for replication of biomarker data is best exemplified by 8-hydroxy-2-deoxyguanosine (8$\mathrm{OHdG}$ ), a marker of DNA damage produced when guanine is oxidised by reactive oxidative species, that was initially thought to be a promising disease severity marker for HD [reviewed by [219]]. 8-OHdG levels were reported to be elevated serum [220], plasma [102] and leukocytes [103] of HD individuals and plasma levels were found to correlate with proximity to projected clinical diagnosis in premanifest HD [221]. However, subsequent studies failed to replicate these findings [222, 223] bringing into question the validity of $8-\mathrm{OHdG}$ as a marker of disease state in HD.

Comparisons can be "statistically significant" (i.e., have a $p<0.05$ ) even if no true relationship is present. 
Table 9

Analytes found to be similar in HD compared to controls

\begin{tabular}{l} 
Analyte \\
\hline Acetyl carnitine (C2) \\
Adenosine diphosphate (ADP \\
Adiponectin \\
Apolipoprotein A1 (ApoA1) \\
Apolipoprotein E (ApoE)
\end{tabular}

Apolipoprotein E (ApoE)

Anthranillic acid

C-peptide

Catalase (CAT)

Dopamine

Fatty acids, free

Folic acid (Vitamin B9)

Follicle-stimulating hormone (FSH)

Glucose

Glutamic Acid (Glu, E)

Glutamine (Gln, Q)

Haemoglobin

Hexose (H1)

Hydroxysphingomyelin C14:1 (SM.OH.C14.1)

Hydroxysphingomyelin C16:1 (SM.OH.C16.1)

Hydroxysphingomyelin C22:1 (SM.OH.C22.1)

Hydroxysphingomyelin C22:2 (SM.OH.C22.2)

Hydroxysphingomyelin C24:1 (SM.OH.C24.1)

Immunoglobulin $\mathrm{G}(\mathrm{IgG})$

Immunoglobulin $\mathrm{M}(\operatorname{IgM})$

Insulin-like factor binding protein-3 (IGF-BP3)

Interleukin-5 (IL-5)

Iron

Kynurenic acid

Lyso-phosphatidylcholine acyl C16:0 (lysoPC.a.C16.0)

Lyso-phosphatidylcholine acyl C16:1 (lysoPC.a.C16.1)

Lyso-phosphatidylcholine acyl C17:0 (lysoPC.a.C17.0)

Lyso-phosphatidylcholine acyl C18:0 (lysoPC.a.C18.0)

Lyso-phosphatidylcholine acyl C18:1 (lysoPC.a.C18.1)

Lyso-phosphatidylcholine acyl C18:2 (lysoPC.a.C18.2)

Lyso-phosphatidylcholine acyl C20:4 (lysoPC.a.C20.4)

Lyso-phosphatidylcholine acyl C28:0 (lysoPC.a.C28.0)

Lyso-phosphatidylcholine acyl C28:1 (lysoPC.a.C28.1)

Myeloperoxidase (MPO)

Norepinephrine

Octadecadienyl carnitine (C18:2)

Octadecenoyl carnitine (C18:1)

Ornithine (Orn)

Osteocalcin

Osteonectin

Phospatidylcholine diacyl C28:1 (PC.aa.C28.1)

Phospatidylcholine diacyl C30:0 (PC.aa.C30.0)

Phospatidylcholine diacyl C32:0 (PC.aa.C32.0)

Phospatidylcholine diacyl C32:1 (PC.aa.C32.1)

Phospatidylcholine diacyl C34:1 (PC.aa.C34.1)

Phospatidylcholine diacyl C34:2 (PC.aa.C34.2)

Phospatidylcholine diacyl C34:3 (PC.aa.C34.3)

Phospatidylcholine diacyl C34:4 (PC.aa.C34.4)

Phospatidylcholine diacyl C36:1 (PC.aa.C36.1)

Phospatidylcholine diacyl C36:2 (PC.aa.C36.2)

\begin{tabular}{|c|c|c|}
\hline \\
\hline \multicolumn{3}{|c|}{$\frac{\text { Blood }}{\text { Result }}$} \\
\hline$=$ & & {$[55,58]$} \\
\hline$=$ & & {$[310,311]$} \\
\hline \multirow[t]{3}{*}{$=$} & TFC [297] & {$[34,297]$} \\
\hline & TMS [297] & \\
\hline & Independence [297] & \\
\hline$=$ & & {$[37,57]$} \\
\hline \multirow[t]{3}{*}{$=$} & Burden [37] & [37] \\
\hline & Depression [37] & \\
\hline & Irritability [37] & \\
\hline$=$ & & {$[108,279]$} \\
\hline$=$ & & {$[63,291]$} \\
\hline$=$ & & {$[105,106]$} \\
\hline$=$ & & {$[55,275]$} \\
\hline$=$ & & {$[34,57]$} \\
\hline$=$ & & {$[41,80,299]$} \\
\hline$=$ & & {$[81,84,312]$} \\
\hline$=$ & & {$[34,38,41,57,60,61,64,80,97$} \\
\hline & & $102,106,278,291,293,313]$ \\
\hline$=$ & & {$[55-57,288,306,314]$} \\
\hline$=$ & & {$[38,55-58,288,306,314]$} \\
\hline$=$ & & {$[80,274]$} \\
\hline$=$ & & {$[55,58]$} \\
\hline$=$ & & {$[55,58]$} \\
\hline$=$ & & {$[55,58]$} \\
\hline$=$ & & {$[55,58]$} \\
\hline$=$ & & {$[55,58]$} \\
\hline$=$ & & {$[55,58]$} \\
\hline$=$ & & {$[24,41,278]$} \\
\hline$=$ & & {$[24,41]$} \\
\hline$=$ & & {$[81,84,161]$} \\
\hline$=$ & & {$[24,33]$} \\
\hline$=$ & & {$[299,300]$} \\
\hline$=$ & & {$[40,108,279]$} \\
\hline$=$ & & {$[55,58]$} \\
\hline$=$ & & {$[55,58]$} \\
\hline$=$ & & {$[55,58]$} \\
\hline$=$ & & {$[55,58]$} \\
\hline$=$ & & {$[55,58]$} \\
\hline$=$ & & {$[55,58]$} \\
\hline$=$ & & {$[55,58]$} \\
\hline$=$ & & {$[55,58]$} \\
\hline$=$ & & {$[55,58]$} \\
\hline$=$ & & {$[31,308]$} \\
\hline$=$ & & {$[84,275]$} \\
\hline$=$ & & {$[55,58]$} \\
\hline$=$ & & {$[55,58]$} \\
\hline$=$ & & {$[38,47,55-58]$} \\
\hline$=$ & Depression [37] & {$[37,57]$} \\
\hline$=$ & CAG [37] & {$[37,57]$} \\
\hline$=$ & & {$[55,58]$} \\
\hline$=$ & & {$[55,58]$} \\
\hline$=$ & & {$[55,58]$} \\
\hline$=$ & & {$[55,58]$} \\
\hline$=$ & & {$[55,58]$} \\
\hline$=$ & & {$[55,58]$} \\
\hline$=$ & & {$[55,58]$} \\
\hline$=$ & & {$[55,58]$} \\
\hline$=$ & & {$[55,58]$} \\
\hline$=$ & & {$[55,58]$} \\
\hline
\end{tabular}


Table 9

(Continued)

\begin{tabular}{|c|c|c|c|}
\hline \multicolumn{4}{|c|}{ Blood } \\
\hline Analyte & Result & Correlates with ... & Reference \\
\hline Phospatidylcholine diacyl C36:3 (PC.aa.C36.3) & $=$ & & {$[55,58]$} \\
\hline Phospatidylcholine diacyl C36:4 (PC.aa.C36.4) & $=$ & & {$[55,58]$} \\
\hline Phospatidylcholine diacyl C36:6 (PC.aa.C36.6) & $=$ & & {$[55,58]$} \\
\hline Phospatidylcholine diacyl C38:3 (PC.aa.C38.3) & $=$ & & {$[55,58]$} \\
\hline Phospatidylcholine diacyl C38:4 (PC.aa.C38.4) & $=$ & & {$[55,58]$} \\
\hline Phospatidylcholine diacyl C38:5 (PC.aa.C38.5) & $=$ & & {$[55,58]$} \\
\hline Phospatidylcholine diacyl C40:2 (PC.aa.C40.2) & $=$ & & {$[55,58]$} \\
\hline Phospatidylcholine diacyl C40:3 (PC.aa.C40.3) & $=$ & & {$[55,58]$} \\
\hline Phospatidylcholine diacyl C40:4 (PC.aa.C40.4) & $=$ & & {$[55,58]$} \\
\hline Phospatidylcholine diacyl C40:5 (PC.aa.C40.5) & $=$ & & {$[55,58]$} \\
\hline Phospatidylcholine diacyl C42:0 (PC.aa.C42.0) & $=$ & & {$[55,58]$} \\
\hline Phospatidylcholine diacyl C42:1 (PC.aa.C42.1) & $=$ & & {$[55,58]$} \\
\hline Phospatidylcholine diacyl C42:2 (PC.aa.C42.2) & $=$ & & {$[55,58]$} \\
\hline Phospatidylcholine diacyl C42:4 (PC.aa.C42.4) & $=$ & & {$[55,58]$} \\
\hline Phospatidylcholine diacyl C42:5 (PC.aa.C42.5) & $=$ & & {$[55,58]$} \\
\hline Phospatidylcholine diacyl C42:6 (PC.aa.C42.6) & $=$ & & {$[55,58]$} \\
\hline Phosphatidylcholine acyl-alkyl C30:0 (PC.ae.C30.0) & $=$ & & {$[55,58]$} \\
\hline Phosphatidylcholine acyl-alkyl C32:1 (PC.ae.C32.1) & $=$ & & {$[55,58]$} \\
\hline Phosphatidylcholine acyl-alkyl C32:2 (PC.ae.C32.2) & $=$ & & {$[55,58]$} \\
\hline Phosphatidylcholine acyl-alkyl C34:1 (PC.ae.C34.1) & $=$ & & {$[55,58]$} \\
\hline Phosphatidylcholine acyl-alkyl C34:2 (PC.ae.C34.2) & $=$ & & {$[55,58]$} \\
\hline Phosphatidylcholine acyl-alkyl C34:3 (PC.ae.C34.3) & $=$ & & {$[55,58]$} \\
\hline Phosphatidylcholine acyl-alkyl C36:1 (PC.ae.C36.1) & $=$ & & {$[55,58]$} \\
\hline Phosphatidylcholine acyl-alkyl C36:2 (PC.ae.C36.2) & $=$ & & {$[55,58]$} \\
\hline Phosphatidylcholine acyl-alkyl C36:3 (PC.ae.C36.3) & $=$ & & {$[55,58]$} \\
\hline Phosphatidylcholine acyl-alkyl C36:4 (PC.ae.C36.4) & $=$ & & {$[55,58]$} \\
\hline Phosphatidylcholine acyl-alkyl C36:5 (PC.ae.C36.5) & $=$ & & {$[55,58]$} \\
\hline Phosphatidylcholine acyl-alkyl C38:2 (PC.ae.C38.2) & $=$ & & {$[55,58]$} \\
\hline Phosphatidylcholine acyl-alkyl C38:3 (PC.ae.C38.3) & $=$ & & {$[55,58]$} \\
\hline Phosphatidylcholine acyl-alkyl C38:4 (PC.ae.C38.4) & $=$ & & {$[55,58]$} \\
\hline Phosphatidylcholine acyl-alkyl C38:5 (PC.ae.C38.5) & $=$ & & {$[55,58]$} \\
\hline Phosphatidylcholine acyl-alkyl C40:2 (PC.ae.C40.2) & $=$ & & {$[55,58]$} \\
\hline Phosphatidylcholine acyl-alkyl C40:3 (PC.ae.C40.3) & $=$ & & {$[55,58]$} \\
\hline Phosphatidylcholine acyl-alkyl C40:4 (PC.ae.C40.4) & $=$ & & {$[55,58]$} \\
\hline Phosphatidylcholine acyl-alkyl C40:5 (PC.ae.C40.5) & $=$ & & {$[55,58]$} \\
\hline Phosphatidylcholine acyl-alkyl C40:6 (PC.ae.C40.6) & $=$ & & {$[55,58]$} \\
\hline Phosphatidylcholine acyl-alkyl C42:1 (PC.ae.C42.1) & $=$ & & {$[55,58]$} \\
\hline Phosphatidylcholine acyl-alkyl C42:2 (PC.ae.C42.2) & $=$ & & {$[55,58]$} \\
\hline Phosphatidylcholine acyl-alkyl C42:3 (PC.ae.C42.3) & $=$ & & {$[55,58]$} \\
\hline Phosphatidylcholine acyl-alkyl C42:4 (PC.ae.C42.4) & $=$ & & {$[55,58]$} \\
\hline Phosphatidylcholine acyl-alkyl C42:5 (PC.ae.C42.5) & $=$ & & {$[55,58]$} \\
\hline Phosphatidylcholine acyl-alkyl C44:4 (PC.ae.C44.4) & $=$ & & {$[55,58]$} \\
\hline Phosphatidylcholine acyl-alkyl C44:5 (PC.ae.C44.5) & $=$ & & {$[55,58]$} \\
\hline Phosphatidylcholine acyl-alkyl C44:6 (PC.ae.C44.6) & $=$ & & {$[55,58]$} \\
\hline Proline (Pro, P) & $=$ & & {$[38,47,55-58,306]$} \\
\hline Protein, total & $=$ & & {$[38,41]$} \\
\hline Quinolinic acid & $=$ & & {$[40,279]$} \\
\hline S100A12 (EN-RAGE) & $=$ & & [37] \\
\hline S100A8-A9 (calprotectin) & $=$ & CAG [37] & [37] \\
\hline & & Burden [37] & \\
\hline Sphingomyelin C16:0 (SM.C16.0) & $=$ & & {$[55,58]$} \\
\hline Sphingomyelin C16:1 (SM.C16.1) & $=$ & & {$[55,58]$} \\
\hline Sphingomyelin C18:0 (SM.C18.0) & $=$ & & {$[55,58]$} \\
\hline Sphingomyelin C18:1 (SM.C18.1) & $=$ & & {$[55,58]$} \\
\hline Sphingomyelin C20:2 (SM.C20.2) & $=$ & & {$[55,58]$} \\
\hline Sphingomyelin C24:0 (SM.C24.0) & $=$ & & {$[55,58]$} \\
\hline Sphingomyelin C24:1 (SM.C24.1) & $=$ & & {$[55,58]$} \\
\hline Sphingomyelin C26:1 (SM.C26.1) & $=$ & & {$[55,58]$} \\
\hline
\end{tabular}


Table 9

(Continued)

\begin{tabular}{|c|c|c|c|}
\hline \multicolumn{4}{|c|}{ Blood } \\
\hline Analyte & Result & Correlates with $\ldots$ & Reference \\
\hline Tetradecenoyl carnitine (C14:1) & $=$ & \multirow{5}{*}{ CAG [315] } & {$[55,58]$} \\
\hline Thyroid Stimulating Hormone (TSH) & $=$ & & {$[36,38,41,63,80,81,84,315]$} \\
\hline Thyroxine (FT4), free & $=$ & & {$[36,80,81,84,315]$} \\
\hline Thyroxine (T4), total & $=$ & & {$[41,315]$} \\
\hline Tiglyl carnitine (C5:1) & $=$ & & {$[55,58]$} \\
\hline Transthyretin (prealbumin) & $=$ & \multirow[t]{2}{*}{ CAG [37] } & {$[37,63]$} \\
\hline Triglycerides & $=$ & & {$[34,57,60,62,63,102,106,279]$} \\
\hline \multirow{3}{*}{ Triiodothyronine (FT3), free } & \multirow[t]{3}{*}{$=$} & Independence [81] & \multirow{3}{*}[80,81,84]{} \\
\hline & & TFC [81] & \\
\hline & & TMS [81] & \\
\hline Urea & $=$ & & {$[38,41]$} \\
\hline Uric acid (UA) & $=$ & & {$[41,63,80,107,310,316]$} \\
\hline Vitamin B12 & $=$ & & {$[41,80,299]$} \\
\hline$\alpha-1$ Antitrypsin & $=$ & & [37] \\
\hline$\gamma$-Glutamyl-transferase (GGT) & $=$ & & {$[106,278]$} \\
\hline \multicolumn{4}{|l|}{$\mathrm{CSF}$} \\
\hline 5-Hydroxyindoleacetic acid (5-HIAA) & $=$ & & {$[286,287]$} \\
\hline Acetylcholinesterase (AChE) & $=$ & & {$[317,318]$} \\
\hline Aspartic acid (Asp, D) & $=$ & & {$[282,289,306]$} \\
\hline Glutamine (Gln, Q) & $=$ & & {$[282,306,314]$} \\
\hline Orexin-A / Hypocretin-1 & $=$ & & {$[319-322]$} \\
\hline Quinolinic acid & $=$ & & {$[301,323,324]$} \\
\hline \multicolumn{4}{|l|}{ Urine } \\
\hline Cortisol & $=$ & & {$[76,84]$} \\
\hline
\end{tabular}

8-OHdG has a high biological variability so it is unsurprising that $8-\mathrm{OHdG}$ measurements yielded false positive results. Elevated $8-\mathrm{OHdG}$ is associated with confounding factors that are common in HD patients including stress [224], depression [225], smoking and low weight [226]. 8-OHdG levels are also influenced by exposure to pollution [227] and polyphenol-rich foods such as vegetables and red wine [228, 229].

The study by Borowsky et al. [223] challenging previous claims that $8 \mathrm{OHdG}$ is a useful clinical biomarker for HD progression is a good example of a well-designed biomarker study that included good practice of carrying out blinded sample analysis, use of independent analytic methods, estimation of accuracy of analytic methods and stringent collection and storage of samples.

\section{Blinded analysis}

Interpretation of data is seldom completely objective and is, as such, vulnerable to prior convictions and conflict of interest [230]. To reduce research bias in biomarker studies, blinded sample analysis and data interpretation is recommended [231, 232].

\section{Biomarker discovery platforms}

In general, there are two principal approaches for biofluid biomarker discovery: targeted and untargeted. The targeted, "pathophysiologic" approach tests a prespecified hypothesis. It involves knowledge of the relevant human physiology and disease processes, allowing the discovery of novel biomarkers that are produced, released, or cleared during the disease process. In contrast, the untargeted approach is an unbiased approach where a range of "omics" profiling technologies are generally used to systematically screen body fluids for novel biomarkers, paving the way to panels of multiple biomarkers that reflect multiple disease mechanisms. Proteomics and metabolomics are increasingly being used for biomarker discovery in neurodegenerative diseases [reviewed by [233] and [234]], including HD [30, 46]. Since the pathophysiology of HD is heterogeneous, with multiple mechanisms involved at every clinical or pathological stage, until the mechanism of HD fully understood, we must be open to novel mechanisms, and untargeted discovery using various "omics" technologies may lead to the discovery of novel markers. An integrated, multi-omics approach combining genomics, transcriptomics, proteomics, 
and metabolomics technologies can simultaneously detect hundreds of molecules simultaneously, some of which can be altered in the disease state which should result in a more complete biomarker fingerprint and give insight to fundamental mechanisms of HD.

To develop accurate markers of disease progression or therapeutic response that are clinically useful, it is necessary to combine data from wet biomarker studies with experimental, clinical and imaging data using systems biology approaches [235].

There are many articles discussing how systems biology and chemometrics can be used for biomarker discovery [236-239]. For example, Feala et al. integrated protein biomarker candidates for traumatic brain injury with publicly available canonical pathways and human protein-protein interaction networks to illustrate how to systematically generate new, testable hypotheses and identify candidate biomarkers [240]. Several tools are available that provide both pathway analysis and multi-omic integration including Open MS from KNIME [241], MetaboAnalyst [242] and XCMS online [243].

\section{Longitudinal studies}

One thing that became evident during the review work conducted was the lack of longitudinal studies. Only a small proportion of original-data studies evaluated HD biomarkers longitudinally. Most of the studies conducted so far are cross-sectional studies, which is a limitation if the aim is to examine the relationship between a change in a clinical measure and the change in a biomarker over time [244, 245]. A longitudinal design, in which the putative biomarker and clinical measure are both measured at least twice, will be useful when developing a disease progression marker. In addition, the duration needs to be long enough to observe a clinically significant change in the criterion used to draw associations with the putative biomarker. For a biomarker to be disease specific, it does not necessarily have to be different from its baseline levels in matched controls. However, levels of a disease specific marker would change with disease progression or in response to specific disease-modulating therapy while remaining constant in the controls during the same time period. Future longitudinal studies that assess the biomarker and clinical measures at several time points over a sufficient follow-up period are warranted to provide sufficient evidence of a biomarker's potential validity [244].
It is encouraging to note that lack of longitudinal studies has already been realised by HD researchers; two large prospective, longitudinal, observational studies PREDICT-HD [246] and TRACK-HD [205] aiming to identify early HD biomarkers should address this issue.

\section{Importance of publishing negative data (Table 9)}

It is important that the biomarker research community publish all data, significant or not. Publication bias has been systematically investigated, particularly in clinical trials [247-249]. It has been demonstrated that studies reporting positive, or statistically significant, results are more likely to be published, and have higher odds of being fully reported [250]. Conversely, negative results are more likely than positive results to be published in journals with lower impact factors [251].

In this review, we have included a table for analytes unlikely to be useful markers for HD, as these markers have been assessed more than once, showing no difference in between HD and control subjects (Table 9). Of limited news value, but important knowledge to the HD biomarker field. Although these analytes do not differ between HD and control cohorts, some have been shown to correlate with specific disease measures as shown in Table 9.

\section{Biobanks}

Biomarker studies require sufficient numbers of properly annotated, well-characterised biospecimens. Good-quality biobanks that collect, store and distribute biospecimens under stringent quality control and assurance measures will be valuable for biomarker research [252]. Development of novel biomarkers is always a long process and optimal use of available resources is required. International collaboration is essential for standardisation of all aspects of biomarker studies, including biobanking procedures and study design, and to enable construction of sufficiently powered cohorts and optimally replicate findings. Lessons can be learned from other research fields. For example, the BioMS network has taken steps to standardise all aspects of biomarker research and validation to optimise biomarkers for multiple sclerosis [253]; the resulting guidelines can be utilised to benefit biomarker studies in HD [215, 254-262]. 


\section{Biomarker qualification}

Biomarker qualification is a mechanism that integrates the use of biomarkers into drug development programs to improve the efficiency and safety of clinical trials testing novel therapeutics [263-265]. The Food and Drug Administration (FDA) and The European Medicines Agency (EMA) have developed regulatory pathways for biomarker integration in clinical trials: the "Biomarker Qualification Program" [120] and "Qualification of Novel Methodologies for Drug Development" [266], respectively. If a biomarker lacks sufficient data to achieve full qualification, the FDA and EMA can publish a Letter of Support (LOS) [267], which provides support that the biomarker has demonstrated promise based on the level of evidence that has been formally provided to regulators.

At present, there are no biofluid biomarkers that are validated as outcome parameters for HD. Biomarker development and subsequent integration into drug development is critical to accelerating effective treatments for HD. Lessons on biomarker qualification can be learned from AD research [263] where new diagnostic criteria have been proposed that integrate pathophysiological biomarkers (imaging and/or biofluid) into all phases of the diagnostic approach to improve on the diagnostic specificity [268-272].

\section{CONCLUSION}

Our review of HD biofluid marker literature shows that no clinically validated biomarkers for HD are yet available, but there are grounds for cautious optimism. A continuous effort to find a reliable, easy to measure biomarker would improve the efficacy of coming HD clinical trials in many ways. For instance, such a biomarker could identify patients with fast and slow disease progression, thereby enabling more refined stratification and statistical analysis. Also, it would increase trial power, thereby decreasing trial duration and the number of volunteers required for the trial, and this in turn would decrease the cost of clinical trials and would expedite drug development. Finally, a reliable biomarker would provide a more objective, quantitative end point compared with the clinically based outcomes currently used in HD trials.

To clone the huntingtin gene took the combined efforts and skills of the 58 coworkers in the Huntington's Disease Collaborative Research Group and many other researchers [1]. Similarly, finding biomarkers that will aid in the development of novel therapies for HD will most likely need a collaborative effort combining the skills of researchers from many disciplines and harmonisation of standard operating procedures will be crucial for successful biomarker discovery and validation.

\section{ACKNOWLEDGMENTS}

The authors would like to thank Denis Silajdžić for assistance with data mining.

\section{CONFLICT OF INTEREST}

The authors have no conflict of interest to report.

\section{SUPPLEMENTARY MATERIAL}

The supplementary material is available in the electronic version of this article: http://dx.doi.org/ 10.3233/JHD-170273.

\section{REFERENCES}

[1] The Huntington's Disease Collaborative Research Group. A novel gene containing a trinucleotide repeat that is expanded and unstable on Huntington's disease chromosomes. The Huntington's Disease Collaborative Research Group. Cell. 1993;72(6):971-83.

[2] Novak MJ, Tabrizi SJ. Huntington's disease. BMJ. 2010;340:c3109.

[3] Wexler NS, Lorimer J, Porter J, Gomez F, Moskowitz C, Shackell E, et al. Venezuelan kindreds reveal that genetic and environmental factors modulate Huntington's disease age of onset. Proc Natl Acad Sci U S A. 2004;101(10):3498-503.

[4] Mahant N, McCusker EA, Byth K, Graham S, Huntington Study Group. Huntington's disease: Clinical correlates of disability and progression. Neurology. 2003;61(8): 1085-92.

[5] Sathasivam K, Hobbs C, Turmaine M, Mangiarini L, Mahal A, Bertaux F, et al. Formation of polyglutamine inclusions in non-CNS tissue. Hum Mol Genet. 1999;8(5):813-22.

[6] van der Burg JM, Bjorkqvist M, Brundin P. Beyond the brain: Widespread pathology in Huntington's disease. Lancet Neurol. 2009;8(8):765-74.

[7] Carroll JB, Bates GP, Steffan J, Saft C, Tabrizi SJ. Treating the whole body in Huntington's disease. Lancet Neurol. 2015;14(11):1135-42.

[8] Biomarkers Definitions Working Group. Biomarkers and surrogate endpoints: Preferred definitions and conceptual framework. Clin Pharmacol Ther. 2001;69(3):89-95.

[9] BEST (Biomarkers, EndpointS, and other Tools) Resource. Silver Spring (MD)2016.

[10] Trojanowski JQ, Growdon JH. A new consensus report on biomarkers for the early antemortem diagnosis of 
Alzheimer disease: Current status, relevance to drug discovery, and recommendations for future research. J Neuropathol Exp Neurol. 1998;57(6):643-4.

[11] Antoniades CA, Watts C. Huntington's disease and cell therapies: Past, present, and future. Methods Mol Biol. 2013;1010:19-32.

[12] Bonelli RM, Wenning GK, Kapfhammer HP. Huntington's disease: Present treatments and future therapeutic modalities. Int Clin Psychopharmacol. 2004;19(2):51-62.

[13] Mason SL, Barker RA. Emerging drug therapies in Huntington's disease. Expert Opin Emerg Drugs. 2009;14(2):273-97.

[14] Zielonka D, Mielcarek M, Landwehrmeyer GB. Update on Huntington's disease: Advances in care and emerging therapeutic options. Parkinsonism Relat Disord. 2015;21(3):169-78.

[15] Tabrizi SJ, Scahill RI, Owen G, Durr A, Leavitt BR, Roos RA, et al. Predictors of phenotypic progression and disease onset in premanifest and early-stage Huntington's disease in the TRACK-HD study: Analysis of 36-month observational data. Lancet Neurol. 2013;12(7):637-49.

[16] Borovecki F, Lovrecic L, Zhou J, Jeong H, Then F, Rosas $\mathrm{HD}$, et al. Genome-wide expression profiling of human blood reveals biomarkers for Huntington's disease. Proc Natl Acad Sci U S A. 2005;102(31):11023-8.

[17] Paulsen JS, Wang C, Duff K, Barker R, Nance $\mathrm{M}$, Beglinger L, et al. Challenges assessing clinical endpoints in early Huntington disease. Mov Disord. 2010;25(15):2595-603.

[18] U.S. Food and Drug Administration (FDA): Challenges and Opportunities Report - March 2004. 2004 [updated 01/25/2016 cited 2018 February]. Available from: http:// www.fda.gov/ScienceResearch/SpecialTopics/CriticalPat hInitiative/CriticalPathOpportunitiesReports/ucm077262. htm.

[19] U.S. Food and Drug Administration (FDA): Critical Path 2010 Update 2010 [updated 04/07/2011; cited 2018 February]. Available from: https://www.fda.gov/ ScienceResearch/SpecialTopics/CriticalPathInitiative/ucm 204289.htm

[20] Valera AG, Diaz-Hernandez M, Hernandez F, Ortega Z, Lucas JJ. The ubiquitin-proteasome system in Huntington's disease. Neuroscientist. 2005;11(6):583-94.

[21] Cha JH. Transcriptional signatures in Huntington's disease. Prog Neurobiol. 2007;83(4):228-48.

[22] Stack EC, Matson WR, Ferrante RJ. Evidence of oxidant damage in Huntington's disease: Translational strategies using antioxidants. Ann N Y Acad Sci. 2008;1147:79-92.

[23] Browne SE. Mitochondria and Huntington's disease pathogenesis: Insight from genetic and chemical models. Ann N Y Acad Sci. 2008;1147:358-82.

[24] Bjorkqvist M, Wild EJ, Thiele J, Silvestroni A, Andre R, Lahiri N, et al. A novel pathogenic pathway of immune activation detectable before clinical onset in Huntington's disease. J Exp Med. 2008;205(8):1869-77.

[25] Moller T. Neuroinflammation in Huntington's disease. J Neural Transm. 2010;117(8):1001-8.

[26] Tai YF, Pavese N, Gerhard A, Tabrizi SJ, Barker RA, Brooks DJ, et al. Microglial activation in presymptomatic Huntington's disease gene carriers. Brain. 2007;130(Pt 7):1759-66.

[27] Sapp E, Kegel KB, Aronin N, Hashikawa T, Uchiyama Y, Tohyama K, et al. Early and progressive accumulation of reactive microglia in the Huntington disease brain. J Neuropathol Exp Neurol. 2001;60(2):161-72.
[28] Pavese N, Gerhard A, Tai YF, Ho AK, Turkheimer F, Barker RA, et al. Microglial activation correlates with severity in Huntington disease: A clinical and PET study. Neurology. 2006;66(11):1638-43.

[29] Ellrichmann G, Reick C, Saft C, Linker RA. The role of the immune system in Huntington's disease. Clin Dev Immunol. 2013;2013:541259.

[30] Dalrymple A, Wild EJ, Joubert R, Sathasivam K, Bjorkqvist M, Petersen A, et al. Proteomic profiling of plasma in Huntington's disease reveals neuroinflammatory activation and biomarker candidates. J Proteome Res. 2007;6(7):2833-40.

[31] Sanchez-Lopez F, Tasset I, Aguera E, Feijoo M, Fernandez-Bolanos R, Sanchez FM, et al. Oxidative stress and inflammation biomarkers in the blood of patients with Huntington's disease. Neurol Res. 2012;34(7): 721-4.

[32] Chang KH, Wu YR, Chen YC, Chen CM. Plasma inflammatory biomarkers for Huntington's disease patients and mouse model. Brain Behav Immun. 2015;44:121-7.

[33] Bouwens JA, van Duijn E, Cobbaert CM, Roos RA, van der Mast RC, Giltay EJ. Plasma cytokine levels in relation to neuropsychiatric symptoms and cognitive dysfunction in Huntington's disease. J Huntingtons Dis. 2016;5(4): 369-77.

[34] Wang R, Ross CA, Cai H, Cong WN, Daimon CM, Carlson $\mathrm{OD}$, et al. Metabolic and hormonal signatures in premanifest and manifest Huntington's disease patients. Front Physiol. 2014;5:231.

[35] Politis M, Lahiri N, Niccolini F, Su P, Wu K, Giannetti P, et al. Increased central microglial activation associated with peripheral cytokine levels in premanifest Huntington's disease gene carriers. Neurobiol Dis. 2015;83:115-21.

[36] Mochel F, Charles P, Seguin F, Barritault J, Coussieu C, Perin L, et al. Early energy deficit in Huntington disease: Identification of a plasma biomarker traceable during disease progression. PLoS One. 2007;2(7):e647.

[37] Silajdzic E, Rezeli M, Vegvari A, Lahiri N, Andre $\mathrm{R}$, Magnusson-Lind A, et al. A critical evaluation of inflammatory markers in Huntington's Disease plasma. J Huntingtons Dis. 2013;2(1):125-34.

[38] Gruber B, Klaczkow G, Jaworska M, Krzyszton-Russjan J, Anuszewska EL, Zielonka D, et al. Huntington' disease-imbalance of amino acid levels in plasma of patients and mutation carriers. Ann Agric Environ Med. 2013;20(4):779-83.

[39] Bouwens JA, Hubers AA, van Duijn E, Cobbaert CM, Roos RA, van der Mast RC, et al. Acute-phase proteins in relation to neuropsychiatric symptoms and use of psychotropic medication in Huntington's disease. Eur Neuropsychopharmacol. 2014;24(8):1248-56.

[40] Stoy N, Mackay GM, Forrest CM, Christofides J, Egerton M, Stone TW, et al. Tryptophan metabolism and oxidative stress in patients with Huntington's disease. J Neurochem. 2005;93(3):611-23.

[41] Leblhuber F, Walli J, Jellinger K, Tilz GP, Widner $\mathrm{B}$, Laccone $\mathrm{F}$, et al. Activated immune system in patients with Huntington's disease. Clin Chem Lab Med. 1998;36(10):747-50.

[42] Widner B, Leblhuber F, Walli J, Tilz GP, Demel U, Fuchs D. Degradation of tryptophan in neurodegenerative disorders. Adv Exp Med Biol. 1999;467:133-8.

[43] Christofides J, Bridel M, Egerton M, Mackay GM, Forrest CM, Stoy N, et al. Blood 5-hydroxytryptamine, 5hydroxyindoleacetic acid and melatonin levels in patients 
with either Huntington's disease or chronic brain injury. J Neurochem. 2006;97(4):1078-88.

[44] Goodman AO, Murgatroyd PR, Medina-Gomez G, Wood NI, Finer N, Vidal-Puig AJ, et al. The metabolic profile of early Huntington's disease-a combined human and transgenic mouse study. Exp Neurol. 2008;210(2): 691-8.

[45] Djousse L, Knowlton B, Cupples LA, Marder K, Shoulson I, Myers RH. Weight loss in early stage of Huntington's disease. Neurology. 2002;59(9):1325-30.

[46] Underwood BR, Broadhurst D, Dunn WB, Ellis DI, Michell AW, Vacher C, et al. Huntington disease patients and transgenic mice have similar pro-catabolic serum metabolite profiles. Brain. 2006;129(Pt 4):877-86.

[47] Reilmann R, Rolf LH, Lange HW. Decreased plasma alanine and isoleucine in Huntington's disease. Acta Neurol Scand. 1995;91(3):222-4.

[48] Mochel F, Benaich S, Rabier D, Durr A. Validation of plasma branched chain amino acids as biomarkers in Huntington disease. Arch Neurol. 2011;68(2):265-7.

[49] Ottosson JO, Rapp W. Serum levels of phenylalanine and tyrosine in Huntington's chorea. Acta Psychiatr Scand Suppl. 1971;221:89-1.

[50] Ottosson JO, Rapp W. Amino acids in Huntington's chorea. Barbeau A, Chase TN, Paulson GW, editors. New York: Raven Press; 1973.

[51] Perry TL, Diamond S, Hansen S, Stedman D. Plasmaaminoacid levels in Huntington's chorea. Lancet. 1969;1(7599):806-8.

[52] Perry TL, Hansen S, Lesk D, Kloster M. Amino acids in plasma, cerebrospinal fluid, and brain of patients with Huntington's chorea. Barbeau A, Chase TN, Paulson GW, editors. New York: Raven Press; 1973.

[53] Phillipson OT, Bird ED. Plasma glucose, non-esterified fatty acids and amino acids in Huntington's chorea. Clin Sci Mol Med. 1977;52(3):311-8.

[54] Yates CM, Magill BE, Davidson D, Murray LG, Wilson $\mathrm{H}$, Pullar IA. Lysosomal enzymes, amino acids and acid metabolites of amines in Huntington's chorea. Clin Chim Acta. 1973;44(1):139-45.

[55] Cheng ML, Chang KH, Wu YR, Chen CM. Metabolic disturbances in plasma as biomarkers for Huntington's disease. J Nutr Biochem. 2016;31:38-44.

[56] Aziz NA, Onkenhout W, Kerstens HJ, Roos RA. Cystathionine levels in patients with Huntington disease. PLoS Curr. 2015;7.

[57] Nambron R, Silajdzic E, Kalliolia E, Ottolenghi C, Hindmarsh P, Hill NR, et al. A metabolic study of Huntington's disease. PLoS One. 2016;11(1):e0146480.

[58] Mastrokolias A, Pool R, Mina E, Hettne KM, van Duijn E, van der Mast RC, et al. Integration of targeted metabolomics and transcriptomics identifies deregulation of phosphatidylcholine metabolism in Huntington's disease peripheral blood samples. Metabolomics. 2016;12:137.

[59] Leoni V, Mariotti C, Tabrizi SJ, Valenza M, Wild EJ, Henley SM, et al. Plasma 24S-hydroxycholesterol and caudate MRI in pre-manifest and early Huntington's disease. Brain. 2008;131(Pt 11):2851-9.

[60] Lalic NM, Maric J, Svetel M, Jotic A, Stefanova E, Lalic K, et al. Glucose homeostasis in Huntington disease: Abnormalities in insulin sensitivity and early-phase insulin secretion. Arch Neurol. 2008;65(4):476-80.

[61] Salvatore E, Rinaldi C, Tucci T, Di Maio L, Di Somma C, Savastano S, et al. Growth hormone response to arginine test differentiates between two subgroups of Huntington's disease patients. J Neurol Neurosurg Psychiatry. 2011;82(5):543-7.

[62] Ciancarelli I, De Amicis D, Di Massimo C, Di Scanno C, Pistarini C, D'Orazio N, et al. Peripheral biomarkers of oxidative stress and their limited potential in evaluation of clinical features of Huntington's patients. Biomarkers. 2014;19(6):452-6.

[63] Sussmuth SD, Muller VM, Geitner C, Landwehrmeyer GB, Iff S, Gemperli A, et al. Fat-free mass and its predictors in Huntington's disease. J Neurol. 2015;262(6): 1533-40.

[64] Ciancarelli I, De Amicis D, Di Massimo C, Sandrini G, Pistarini C, Carolei A, et al. Influence of intensive multifunctional neurorehabilitation on neuronal oxidative damage in patients with Huntington's disease. Funct Neurol. 2015;30(1):47-52.

[65] Leoni V, Mariotti C, Nanetti L, Salvatore E, Squitieri F, Bentivoglio AR, et al. Whole body cholesterol metabolism is impaired in Huntington's disease. Neurosci Lett. 2011;494(3):245-9.

[66] Leoni V, Long JD, Mills JA, Di Donato S, Paulsen JS, PREDICT-HD study group. Plasma 24S-hydroxycholesterol correlation with markers of Huntington disease progression. Neurobiol Dis. 2013;55:37-43.

[67] Vonsattel JP, Myers RH, Stevens TJ, Ferrante RJ, Bird ED, Richardson EP, Jr. Neuropathological classification of Huntington's disease. J Neuropathol Exp Neurol. 1985;44(6):559-77.

[68] Brandt J. Cognitive impairments in Huntington's disease: Insights into the neuropsychology of the striatum. In: Boller F, Grafman J, eds. Handbook of neuropsychology. 5. Amsterdam: Elsevier; 1991. pp. 241-64.

[69] Kassubek J, Juengling FD, Kioschies T, Henkel K, Karitzky J, Kramer B, et al. Topography of cerebral atrophy in early Huntington's disease: A voxel based morphometric MRI study. J Neurol Neurosurg Psychiatry. 2004;75(2):213-20.

[70] Kremer HP, Roos RA, Dingjan G, Marani E, Bots GT. Atrophy of the hypothalamic lateral tuberal nucleus in Huntington's disease. J Neuropathol Exp Neurol. 1990;49(4):371-82.

[71] Kremer HP, Roos RA, Dingjan GM, Bots GT, Bruyn GW, Hofman MA. The hypothalamic lateral tuberal nucleus and the characteristics of neuronal loss in Huntington's disease. Neurosci Lett. 1991;132(1):101-4.

[72] Petersen A, Gil J, Maat-Schieman ML, Bjorkqvist M, Tanila H, Araujo IM, et al. Orexin loss in Huntington's disease. Hum Mol Genet. 2005;14(1):39-47.

[73] Adamczak-Ratajczak A, Kupsz J, Owecki M, Zielonka D, Sowinska A, Checinska-Maciejewska Z, et al. Circadian rhythms of melatonin and cortisol in manifest Huntington's disease and in acute cortical ischemic stroke. J Physiol Pharmacol. 2017;68(4):539-46.

[74] Aziz NA, Pijl H, Frolich M, Schroder-van der Elst JP, van der Bent C, Roelfsema F, et al. Delayed onset of the diurnal melatonin rise in patients with Huntington's disease. J Neurol. 2009;256(12):1961-5.

[75] Kalliolia E, Silajdzic E, Nambron R, Hill NR, Doshi A, Frost C, et al. Plasma melatonin is reduced in Huntington's disease. Mov Disord. 2014;29(12):1511-5.

[76] Aziz NA, Pijl H, Frolich M, van der Graaf AW, Roelfsema F, Roos RA. Increased hypothalamic-pituitary-adrenal axis activity in Huntington's disease. J Clin Endocrinol Metab. 2009;94(4):1223-8. 
[77] Bjorkqvist M, Petersen A, Bacos K, Isaacs J, Norlen P, Gil J, et al. Progressive alterations in the hypothalamicpituitary-adrenal axis in the R6/2 transgenic mouse model of Huntington's disease. Hum Mol Genet. 2006;15(10):1713-21.

[78] Heuser IJ, Chase TN, Mouradian MM. The limbichypothalamic-pituitary-adrenal axis in Huntington's disease. Biol Psychiatry. 1991;30(9):943-52.

[79] Kurlan R, Caine E, Rubin A, Nemeroff CB, Bissette G, Zaczek R, et al. Cerebrospinal fluid correlates of depression in Huntington's disease. Arch Neurol. 1988;45(8):881-3

[80] Leblhuber F, Peichl M, Neubauer C, Reisecker F, Steinparz FX, Windhager E, et al. Serum dehydroepiandrosterone and cortisol measurements in Huntington's chorea. J Neurol Sci. 1995;132(1):76-9.

[81] Saleh N, Moutereau S, Durr A, Krystkowiak P, Azulay JP, Tranchant C, et al. Neuroendocrine disturbances in Huntington's disease. PLoS one. 2009;4(3):e4962.

[82] Hubers AA, van der Mast RC, Pereira AM, Roos RA, Veen LJ, Cobbaert CM, et al. Hypothalamic-pituitaryadrenal axis functioning in Huntington's disease and its association with depressive symptoms and suicidality. J Neuroendocrinol. 2015;27(3):234-44.

[83] van Duijn E, Selis MA, Giltay EJ, Zitman FG, Roos $\mathrm{RA}$, van Pelt $\mathrm{H}$, et al. Hypothalamic-pituitary-adrenal axis functioning in Huntington's disease mutation carriers compared with mutation-negative first-degree controls. Brain Res Bull. 2010;83(5):232-7.

[84] Kalliolia E, Silajdzic E, Nambron R, Costelloe SJ, Martin NG, Hill NR, et al. A 24-hour study of the hypothalamo-pituitary axes in Huntington's disease. PLoS One. 2015;10(10):e0138848.

[85] Markianos M, Panas M, Kalfakis N, Vassilopoulos D. Plasma testosterone, dehydroepiandrosterone sulfate, and cortisol in female patients with Huntington's disease. Neuro Endocrinol Lett. 2007;28(2):199-203.

[86] Shirbin CA, Chua P, Churchyard A, Lowndes G, Hannan AJ, Pang TY, et al. Cortisol and depression in pre-diagnosed and early stage Huntington's disease. Psychoneuroendocrinology. 2013;38(11):2439-47.

[87] Carroll BJ, Curtis GC, Mendels J. Neuroendocrine regulation in depression. II. Discrimination of depressed from nondepressed patients. Arch Gen Psychiatry. 1976;33(9):1051-8.

[88] Halbreich U, Asnis GM, Shindledecker R, Zumoff B, Nathan RS. Cortisol secretion in endogenous depression. I. Basal plasma levels. Arch Gen Psychiatry. 1985;42(9):904-8.

[89] Rubin RT, Poland RE, Lesser IM, Winston RA, Blodgett AL. Neuroendocrine aspects of primary endogenous depression. I. Cortisol secretory dynamics in patients and matched controls. Arch Gen Psychiatry. 1987;44(4): 328-36.

[90] Young EA, Carlson NE, Brown MB. Twenty-four-hour ACTH and cortisol pulsatility in depressed women. Neuropsychopharmacology. 2001;25(2):267-76.

[91] Russell E, Koren G, Rieder M, Van Uum S. Hair cortisol as a biological marker of chronic stress: Current status, future directions and unanswered questions. Psychoneuroendocrinology. 2012;37(5):589-601.

[92] Phillipson OT, Bird ED. Plasma growth hormone concentrations in Huntington's chorea. Clin Sci Mol Med. 1976;50(6):551-4.
[93] Durso R, Tamminga CA, Ruggeri S, Denaro A, Kuo S, Chase TN. Twenty-four hour plasma levels of growth hormone and prolactin in Huntington's disease. J Neurol Neurosurg Psychiatry. 1983;46(12):1134-7.

[94] Chalmers RJ, Johnson RH, Keogh HJ, Nanda RN. Growth hormone and prolactin response to bromocriptine in patients with Huntington's chorea. J Neurol Neurosurg Psychiatry. 1978;41(2):135-9.

[95] Levy CL, Carlson HE, Sowers JR, Goodlett RE, Tourtellotte WW, Hershman JM. Growth hormone and prolactin secretion in Huntington's disease. Life Sci. 1979;24(8):743-9.

[96] Murri L, Iudice A, Muratorio A, Polleri A, Barreca T, Murialdo G. Spontaneous nocturnal plasma prolactin and growth hormone secretion in patients with Parkinson's disease and Huntington's chorea. Eur Neurol. 1980;19(3):198-206.

[97] Popovic V, Svetel M, Djurovic M, Petrovic S, Doknic M, Pekic S, et al. Circulating and cerebrospinal fluid ghrelin and leptin: Potential role in altered body weight in Huntington's disease. Eur J Endocrinol. 2004;151(4):451-5.

[98] Browne SE, Ferrante RJ, Beal MF. Oxidative stress in Huntington's disease. Brain Pathol. 1999;9(1):147-63.

[99] Johri A, Beal MF. Antioxidants in Huntington's disease. Biochim Biophys Acta. 2012;1822(5):664-74.

[100] Trushina E, McMurray CT. Oxidative stress and mitochondrial dysfunction in neurodegenerative diseases. Neuroscience. 2007;145(4):1233-48.

[101] Sayre LM, Perry G, Smith MA. Oxidative stress and neurotoxicity. Chem Res Toxicol. 2008;21(1):172-88.

[102] Tunez I, Sanchez-Lopez F, Aguera E, Fernandez-Bolanos R, Sanchez FM, Tasset-Cuevas I. Important role of oxidative stress biomarkers in Huntington's disease. J Med Chem. 2011;54(15):5602-6.

[103] Chen CM, Wu YR, Cheng ML, Liu JL, Lee YM, Lee PW, et al. Increased oxidative damage and mitochondrial abnormalities in the peripheral blood of Huntington's disease patients. Biochem Biophys Res Commun. 2007;359(2):335-40.

[104] Duran R, Barrero FJ, Morales B, Luna JD, Ramirez M, Vives F. Oxidative stress and plasma aminopeptidase activity in Huntington's disease. J Neural Transm (Vienna). 2010;117(3):325-32.

[105] Klepac N, Relja M, Klepac R, Hecimovic S, Babic T, Trkulja V. Oxidative stress parameters in plasma of Huntington's disease patients, asymptomatic Huntington's disease gene carriers and healthy subjects: A crosssectional study. J Neurol. 2007;254(12):1676-83.

[106] Pena-Sanchez M, Riveron-Forment G, Zaldivar-Vaillant T, Soto-Lavastida A, Borrero-Sanchez J, Lara-Fernandez G, et al. Association of status redox with demographic, clinical and imaging parameters in patients with Huntington's disease. Clin Biochem. 2015;48(18):1258-63.

[107] Rosas HD, Doros G, Bhasin S, Thomas B, Gevorkian S, Malarick K, et al. A systems-level "misunderstanding": The plasma metabolome in Huntington's disease. Ann Clin Transl Neurol. 2015;2(7):756-68.

[108] Forrest CM, Mackay GM, Stoy N, Spiden SL, Taylor R, Stone TW, et al. Blood levels of kynurenines, interleukin-23 and soluble human leucocyte antigen-G at different stages of Huntington's disease. J Neurochem. 2010;112(1):112-22.

[109] Constantinescu R, Romer M, Oakes D, Rosengren L, Kieburtz K. Levels of the light subunit of neurofilament 
triplet protein in cerebrospinal fluid in Huntington's disease. Parkinsonism Relat Disord. 2009;15(3):245-8.

[110] Rodrigues FB, Byrne LM, McColgan P, Robertson N, Tabrizi SJ, Zetterberg H, et al. Cerebrospinal fluid inflammatory biomarkers reflect clinical severity in Huntington's disease. PLoS One. 2016;11(9):e0163479.

[111] Vinther-Jensen T, Bornsen L, Budtz-Jorgensen E, Ammitzboll C, Larsen IU, Hjermind LE, et al. Selected CSF biomarkers indicate no evidence of early neuroinflammation in Huntington disease. Neurol Neuroimmunol Neuroinflamm. 2016;3(6):e287.

[112] Byrne LM, Rodrigues FB, Blennow K, Durr A, Leavitt BR, Roos RAC, et al. Neurofilament light protein in blood as a potential biomarker of neurodegeneration in Huntington's disease: A retrospective cohort analysis. Lancet Neurol. 2017;16(8):601-9.

[113] Niemela V, Landtblom AM, Blennow K, Sundblom J. Tau or neurofilament light-Which is the more suitable biomarker for Huntington's disease? PLoS One. 2017;12(2):e0172762.

[114] Wild EJ, Boggio R, Langbehn D, Robertson N, Haider S, Miller JR, et al. Quantification of mutant huntingtin protein in cerebrospinal fluid from Huntington's disease patients. J Clin Invest. 2015;125(5):1979-86.

[115] Johnson EB, Byrne LM, Gregory S, Rodrigues FB, Blennow K, Durr A, et al. Neurofilament light protein in blood predicts regional atrophy in Huntington disease. Neurology. 2018;90(8):e717-e723.

[116] Constantinescu R, Romer M, Zetterberg H, Rosengren L, Kieburtz K. Increased levels of total tau protein in the cerebrospinal fluid in Huntington's disease. Parkinsonism Relat Disord. 2011;17(9):714-5.

[117] Fang Q, Strand A, Law W, Faca VM, Fitzgibbon MP, Hamel N, et al. Brain-specific proteins decline in the cerebrospinal fluid of humans with Huntington disease. Mol Cell Proteomics. 2009;8(3):451-66.

[118] Rodrigues FB, Byrne L, McColgan P, Robertson N, Tabrizi SJ, Leavitt BR, et al. Cerebrospinal fluid total tau concentration predicts clinical phenotype in Huntington's disease. J Neurochem. 2016;139(1):22-5.

[119] Southwell AL, Smith SE, Davis TR, Caron NS, Villanueva $\mathrm{EB}, \mathrm{Xie} \mathrm{Y}$, et al. Ultrasensitive measurement of huntingtin protein in cerebrospinal fluid demonstrates increase with Huntington disease stage and decrease following brain huntingtin suppression. Sci Rep. 2015;5: 12166.

[120] U.S. Food \& Drug Administration (FDA): Biomarker Qualification Program 2017 [updated 12/06/2017; cited 2018 February]. Available from: http://www.fda. gov/BiomarkerQualificationProgram/.

[121] U.S. Food and Drug Administration (FDA): Context of Use for Biomarker Qualification 2017 [updated 25/08/2017; cited 2018 February]. Available from: https:// www.fda.gov/Drugs/DevelopmentApprovalProcess/Drug DevelopmentToolsQualificationProgram/BiomarkerQuali ficationProgram/ucm535395.htm.

[122] Zhou C, Simpson KL, Lancashire LJ, Walker MJ, Dawson MJ, Unwin RD, et al. Statistical considerations of optimal study design for human plasma proteomics and biomarker discovery. J Proteome Res. 2012;11(4):2103-13.

[123] Issaq HJ, Veenstra TD. Proteomic and metabolomic approaches to biomarker discovery. Academic Press; 2013.
[124] Rundle A, Ahsan H, Vineis P. Better cancer biomarker discovery through better study design. Eur J Clin Invest. 2012;42(12):1350-9.

[125] Gosho M, Nagashima K, Sato Y. Study designs and statistical analyses for biomarker research. Sensors. 2012;12(7):8966-86.

[126] Overfield T. Biologic variation in health and illness: Race, age, and sex differences. 2nd ed. Boca Raton; London: CRC Press; 1995. pp. 203.

[127] Fraser CG. Biological Variation: From Principles to Practice. Washington, DC: AACC Press; 2001.

[128] Czeisler CA, Klerman EB. Circadian and sleep-dependent regulation of hormone release in humans. Recent Prog Horm Res. 1999;54:97-130; discussion -2.

[129] Rossmanith WG, Lauritzen C. The luteinizing hormone pulsatile secretion: Diurnal excursions in normally cycling and postmenopausal women. Gynecol Endocrinol. 1991;5(4):249-65.

[130] Reed BG, Carr BR. The normal menstrual cycle and the control of ovulation. In: De Groot LJ, Chrousos G, Dungan K, Feingold KR, Grossman A, Hershman JM, et al., editors. Endotext. South Dartmouth (MA); 2000.

[131] Gordon DJ, Trost DC, Hyde J, Whaley FS, Hannan PJ, Jacobs DR, Jr., et al. Seasonal cholesterol cycles: The Lipid Research Clinics Coronary Primary Prevention Trial placebo group. Circulation. 1987;76(6):1224-31.

[132] Ockene IS, Chiriboga DE, Stanek EJ 3rd, Harmatz MG, Nicolosi R, Saperia G, et al. Seasonal variation in serum cholesterol levels: Treatment implications and possible mechanisms. Arch Intern Med. 2004;164(8):863-70.

[133] Maxwell JD. Seasonal variation in vitamin D. Proc Nutr Soc. 1994;53(3):533-43.

[134] Larsson CA, Gullberg B, Rastam L, Lindblad U. Salivary cortisol differs with age and sex and shows inverse associations with WHR in Swedish women: A cross-sectional study. BMC Endocr Disord. 2009;9:16.

[135] Van Cauter E, Leproult R, Kupfer DJ. Effects of gender and age on the levels and circadian rhythmicity of plasma cortisol. J Clin Endocrinol Metab. 1996;81(7):2468-73.

[136] Vakkuri O, Kivela A, Leppaluoto J, Valtonen M, Kauppila A. Decrease in melatonin precedes folliclestimulating hormone increase during perimenopause. Eur J Endocrinol. 1996;135(2):188-92.

[137] Apter D, Cacciatore B, Alfthan H, Stenman UH. Serum luteinizing hormone concentrations increase 100-fold in females from 7 years to adulthood, as measured by timeresolved immunofluorometric assay. J Clin Endocrinol Metab. 1989;68(1):53-7.

[138] Ziegler MG, Lake CR, Kopin IJ. Plasma noradrenaline increases with age. Nature. 1976;261(5558):333-5.

[139] Sack RL, Lewy AJ, Erb DL, Vollmer WM, Singer CM. Human melatonin production decreases with age. J Pineal Res. 1986;3(4):379-88.

[140] Bauer JH. Age-related changes in the renin-aldosterone system. Physiological effects and clinical implications. Drugs Aging. 1993;3(3):238-45.

[141] Weidmann P, De Myttenaere-Bursztein S, Maxwell MH, de Lima J. Effect on aging on plasma renin and aldosterone in normal man. Kidney Int. 1975;8(5):325-33.

[142] Sonntag WE, Lynch CD, Cooney PT, Hutchins PM. Decreases in cerebral microvasculature with age are associated with the decline in growth hormone and insulin-like growth factor 1. Endocrinology. 1997;138(8):3515-20. 
[143] Lamberts SW, van den Beld AW, van der Lely AJ. The endocrinology of aging. Science. 1997;278(5337):419-24.

[144] Vekemans M, Robyn C. Influence of age on serum prolactin levels in women and men. Br Med J. 1975; 4(5999):738-9.

[145] Lehmann M, Keul J. Urinary excretion of free noradrenaline and adrenaline related to age, sex and hypertension in 265 individuals. Eur J Appl Physiol Occup Physiol 1986;55(1):14-8.

[146] Mooy JM, Grootenhuis PA, de Vries H, Kostense PJ, PoppSnijders C, Bouter LM, et al. Intra-individual variation of glucose, specific insulin and proinsulin concentrations measured by two oral glucose tolerance tests in a general Caucasian population: The Hoorn Study. Diabetologia. 1996;39(3):298-305.

[147] Mariotti S, Franceschi C, Cossarizza A, Pinchera A. The aging thyroid. Endocr Rev. 1995;16(6):686-715.

[148] Catoire M, Mensink M, Kalkhoven E, Schrauwen P, Kersten S. Identification of human exercise-induced myokines using secretome analysis. Physiol Genomics. 2014;46(7):256-67.

[149] Muller EE, Cocchi D, Mantegazza P, Parati EA, Caraceni T. Prolactin control in Huntington's chorea. Lancet. 1977;2(8041):764-5.

[150] Melkersson KI, Hulting AL, Brismar KE. Elevated levels of insulin, leptin, and blood lipids in olanzapine-treated patients with schizophrenia or related psychoses. J Clin Psychiatry. 2000;61(10):742-9.

[151] Tzoulaki I, Siontis KC, Ioannidis JP. Prognostic effect size of cardiovascular biomarkers in datasets from observational studies versus randomised trials: Metaepidemiology study. BMJ. 2011;343:d6829.

[152] The Best Practice Advocacy Centre New Zealand (bpacnz): Factors that can affect laboratory investigations 2015 [updated 26/04/2015; cited 2018 February]. Available from: https://bpac.org.nz/BT/2015/April/laboratoryinvestigations.aspx.

[153] Sottas PE, Kapke GF, Vesterqvist O, Leroux JM. Patientspecific measures of a biomarker for the generation of individual reference intervals: Hemoglobin as example. Transl Res. 2011;158(6):360-8.

[154] Braga F, Panteghini M. Biologic variability of C-reactive protein: Is the available information reliable? Clin Chim Acta. 2012;413(15-16):1179-83.

[155] Gomez-Marcos MA, Recio-Rodriguez JI, Patino-Alonso MC, Agudo-Conde C, Gomez-Sanchez L, RodriguezSanchez E, et al. Relationships between high-sensitive $\mathrm{C}$-reactive protein and markers of arterial stiffness in hypertensive patients. Differences by sex. BMC Cardiovasc Disord. 2012;12:37.

[156] Koikkalainen J, Polonen H, Mattila J, van Gils M, Soininen $\mathrm{H}$, Lotjonen J, et al. Improved classification of Alzheimer's disease data via removal of nuisance variability. PLoS One. 2012;7(2):e31112.

[157] Pourhoseingholi MA, Baghestani AR, Vahedi M. How to control confounding effects by statistical analysis. Gastroenterol Hepatol Bed Bench. 2012;5(2):79-83.

[158] Jager KJ, Zoccali C, Macleod A, Dekker FW. Confounding: What it is and how to deal with it. Kidney Int. 2008;73(3):256-60.

[159] Lima-Oliveira G, Volanski W, Lippi G, Picheth G, Guidi GC. Pre-analytical phase management: A review of the procedures from patient preparation to laboratory analysis. Scand J Clin Lab Invest. 2017;77(3):153-63.
[160] O'Bryant SE, Gupta V, Henriksen K, Edwards M, Jeromin A, Lista $\mathrm{S}$, et al. Guidelines for the standardization of preanalytic variables for blood-based biomarker studies in Alzheimer's disease research. Alzheimers Dement. 2015;11(5):549-60.

[161] Aziz NA, Pijl H, Frolich M, Schroder-van der Elst JP, van der Bent $\mathrm{C}$, Roelfsema $\mathrm{F}$, et al. Growth hormone and ghrelin secretion are associated with clinical severity in Huntington's disease. Eur J Neurol. 2010;17(2): 280-8.

[162] Knudsen LS, Christensen IJ, Lottenburger T, Svendsen MN, Nielsen HJ, Nielsen L, et al. Pre-analytical and biological variability in circulating interleukin 6 in healthy subjects and patients with rheumatoid arthritis. Biomarkers. 2008;13(1):59-78.

[163] Hammouda O, Chtourou H, Chahed H, Ferchichi S, Kallel $\mathrm{C}$, Miled A, et al. Diurnal variations of plasma homocysteine, total antioxidant status, and biological markers of muscle injury during repeated sprint: Effect on performance and muscle fatigue-a pilot study. Chronobiol Int. 2011;28(10):958-67.

[164] Morris CJ, Aeschbach D, Scheer FA. Circadian system, sleep and endocrinology. Mol Cell Endocrinol. 2012;349(1):91-104.

[165] Ota T, Fustin JM, Yamada H, Doi M, Okamura H. Circadian clock signals in the adrenal cortex. Mol Cell Endocrinol. 2012;349(1):30-7.

[166] Mirjanic-Azaric B, Stojakovic-Jelisavac T, Vukovic B, Stojanovic D, Vujnic M, Uletilovic S. The impact of time of sample collection on the measurement of thyroid stimulating hormone values in the serum. Clin Biochem. 2015;48(18):1347-9.

[167] Ho KY, Veldhuis JD, Johnson ML, Furlanetto R, Evans WS, Alberti KG, et al. Fasting enhances growth hormone secretion and amplifies the complex rhythms of growth hormone secretion in man. J Clin Invest. 1988;81(4): 968-75.

[168] Daly M. Sugars, insulin sensitivity, and the postprandial state. Am J Clin Nutr. 2003;78(4):865S-72S.

[169] Barkoukis H, Marchetti CM, Nolan B, Sistrun SN, Krishnan RK, Kirwan JP. A high glycemic meal suppresses the postprandial leptin response in normal healthy adults. Ann Nutr Metab. 2007;51(6):512-8.

[170] Zhou X, Fragala MS, McElhaney JE, Kuchel GA. Conceptual and methodological issues relevant to cytokine and inflammatory marker measurements in clinical research. Curr Opin Clin Nutr Metab Care. 2010;13(5): $541-7$.

[171] Grimble RF, Tappia PS. Modulation of pro-inflammatory cytokine biology by unsaturated fatty acids. Z Ernahrungswiss. 1998;37 Suppl 1:57-65.

[172] Payette C, Blackburn P, Lamarche B, Tremblay A, Bergeron J, Lemieux I, et al. Sex differences in postprandial plasma tumor necrosis factor-alpha, interleukin-6, and C-reactive protein concentrations. Metabolism. 2009;58(11):1593-601.

[173] Esposito K, Nappo F, Marfella R, Giugliano G, Giugliano $\mathrm{F}$, Ciotola $\mathrm{M}$, et al. Inflammatory cytokine concentrations are acutely increased by hyperglycemia in humans: Role of oxidative stress. Circulation. 2002;106(16): 2067-72.

[174] Carroll MF, Schade DS. Timing of antioxidant vitamin ingestion alters postprandial proatherogenic serum markers. Circulation. 2003;108(1):24-31. 
[175] Plumelle D, Lombard E, Nicolay A, Portugal H. Influence of diet and sample collection time on 77 laboratory tests on healthy adults. Clin Biochem. 2014;47(1-2):31-7.

[176] Wedge DC, Allwood JW, Dunn W, Vaughan AA, Simpson $\mathrm{K}$, Brown $\mathrm{M}$, et al. Is serum or plasma more appropriate for intersubject comparisons in metabolomic studies? An assessment in patients with small-cell lung cancer. Anal Chem. 2011;83(17):6689-97.

[177] Breier M, Wahl S, Prehn C, Fugmann M, Ferrari U, Weise $\mathrm{M}$, et al. Targeted metabolomics identifies reliable and stable metabolites in human serum and plasma samples. PLoS One. 2014;9(2):e89728.

[178] Yu Z, Kastenmuller G, He Y, Belcredi P, Moller G, Prehn $C$, et al. Differences between human plasma and serum metabolite profiles. PLoS One. 2011;6(7):e21230.

[179] Yi J, Liu Z, Craft D, O’Mullan P, Ju G, Gelfand CA. Intrinsic peptidase activity causes a sequential multi-step reaction (SMSR) in digestion of human plasma peptides. J Proteome Res. 2008;7(12):5112-8.

[180] O'Mullan P, Craft D, Yi J, Gelfand CA. Thrombin induces broad spectrum proteolysis in human serum samples. Clin Chem Lab Med. 2009;47(6):685-93.

[181] Evans MJ, Livesey JH, Ellis MJ, Yandle TG. Effect of anticoagulants and storage temperatures on stability of plasma and serum hormones. Clin Biochem. 2001;34(2):107-12.

[182] Kohek M, Leme C, Nakamura IT, De Oliveira SA, Lando V, Mendonca BB. Effects of EDTA and Sodium Citrate on hormone measurements by fluorometric (FIA) and immunofluorometric (IFMA) methods. BMC Clin Pathol. 2002;2(1):2.

[183] Denery JR, Nunes AA, Dickerson TJ. Characterization of differences between blood sample matrices in untargeted metabolomics. Anal Chem. 2011;83(3):1040-7.

[184] Cuhadar S, Atay A, Koseoglu M, Dirican A, Hur A. Stability studies of common biochemical analytes in serum separator tubes with or without gel barrier subjected to various storage conditions. Biochem Med (Zagreb). 2012;22(2):202-14.

[185] Bowen RA, Hortin GL, Csako G, Otanez OH, Remaley AT. Impact of blood collection devices on clinical chemistry assays. Clin Biochem. 2010;43(1-2):4-25.

[186] Jorgenrud B, Jantti S, Mattila I, Poho P, Ronningen KS, Yki-Jarvinen $\mathrm{H}$, et al. The influence of sample collection methodology and sample preprocessing on the blood metabolic profile. Bioanalysis. 2015;7(8):991-1006.

[187] Bowen RA, Remaley AT. Interferences from blood collection tube components on clinical chemistry assays. Biochem Med (Zagreb). 2014;24(1):31-44.

[188] Ayache S, Panelli M, Marincola FM, Stroncek DF. Effects of storage time and exogenous protease inhibitors on plasma protein levels. Am J Clin Pathol. 2006;126(2): 174-84.

[189] Zuccato C, Marullo M, Vitali B, Tarditi A, Mariotti $\mathrm{C}$, Valenza $\mathrm{M}$, et al. Brain-derived neurotrophic factor in patients with Huntington's disease. PLoS One. 2011;6(8):e22966.

[190] Aziz N, Detels R, Quint JJ, Li Q, Gjertson D, Butch AW. Stability of cytokines, chemokines and soluble activation markers in unprocessed blood stored under different conditions. Cytokine. 2016;84:17-24.

[191] van de Merbel N, Savoie N, Yadav M, Ohtsu Y, White J, Riccio MF, et al. Stability: Recommendation for best practices and harmonization from the Global Bioanalysis Consortium Harmonization Team. AAPS J. 2014;16(3):392-9.
[192] Trajkovska V, Marcussen AB, Vinberg M, Hartvig P, Aznar S, Knudsen GM. Measurements of brain-derived neurotrophic factor: Methodological aspects and demographical data. Brain Res Bull. 2007;73(1-3):143-9.

[193] Cuhadar S, Koseoglu M, Atay A, Dirican A. The effect of storage time and freeze-thaw cycles on the stability of serum samples. Biochem Med (Zagreb). 2013;23(1):70-7.

[194] Dakappagari N, Zhang H, Stephen L, Amaravadi L, Khan MU. Recommendations for clinical biomarker specimen preservation and stability assessments. Bioanalysis. 2017;9(8):643-53.

[195] Guo GH, Dong J, Yuan XH, Dong ZN, Tian YP. Clinical evaluation of the levels of 12 cytokines in serum/plasma under various storage conditions using evidence biochip arrays. Mol Med Rep. 2013;7(3):775-80.

[196] Leitao MJ, Baldeiras I, Herukka SK, Pikkarainen M, Leinonen V, Simonsen AH, et al. Chasing the effects of pre-analytical confounders - a multicenter study on CSFAD biomarkers. Front Neurol. 2015;6:153.

[197] Ellervik C, Vaught J. Preanalytical variables affecting the integrity of human biospecimens in biobanking. Clin Chem. 2015;61(7):914-34.

[198] Tuck MK, Chan DW, Chia D, Godwin AK, Grizzle WE, Krueger KE, et al. Standard operating procedures for serum and plasma collection: Early detection research network consensus statement standard operating procedure integration working group. J Proteome Res. 2009;8(1):113-7.

[199] Fujimura H, Altar CA, Chen R, Nakamura T, Nakahashi $\mathrm{T}$, Kambayashi J, et al. Brain-derived neurotrophic factor is stored in human platelets and released by agonist stimulation. Thromb Haemost. 2002;87(4):728-34.

[200] Tang SW, Chu E, Hui T, Helmeste D, Law C. Influence of exercise on serum brain-derived neurotrophic factor concentrations in healthy human subjects. Neurosci Lett. 2008;431(1):62-5.

[201] Mitoma M, Yoshimura R, Sugita A, Umene W, Hori $\mathrm{H}$, Nakano $\mathrm{H}$, et al. Stress at work alters serum brain-derived neurotrophic factor (BDNF) levels and plasma 3-methoxy-4-hydroxyphenylglycol (MHPG) levels in healthy volunteers: BDNF and MHPG as possible biological markers of mental stress? Prog Neuropsychopharmacol Biol Psychiatry. 2008;32(3):679-85.

[202] Lommatzsch M, Zingler D, Schuhbaeck K, Schloetcke K, Zingler C, Schuff-Werner P, et al. The impact of age, weight and gender on BDNF levels in human platelets and plasma. Neurobiol Aging. 2005;26(1):115-23.

[203] Bus BA, Molendijk ML, Penninx BJ, Buitelaar JK, Kenis G, Prickaerts J, et al. Determinants of serum brainderived neurotrophic factor. Psychoneuroendocrinology. 2011;36(2):228-39.

[204] Tsuchimine S, Sugawara N, Ishioka M, Yasui-Furukori N. Preanalysis storage conditions influence the measurement of brain-derived neurotrophic factor levels in peripheral blood. Neuropsychobiology. 2014;69(2):83-8.

[205] Tabrizi SJ, Langbehn DR, Leavitt BR, Roos RA, Durr A, Craufurd D, et al. Biological and clinical manifestations of Huntington's disease in the longitudinal TRACK-HD study: Cross-sectional analysis of baseline data. Lancet Neurol. 2009;8(9):791-801.

[206] European Huntington's Disease Network (EHDN) [cited 2018 February]. Available from: http://www.ehdn.org.

[207] BioRep Research Network [cited 2018 February]. Available from: http://www.biorep.it/en/biological-resourcescenter/research-network. 
[208] Khoury GA, Baliban RC, Floudas CA. Proteome-wide post-translational modification statistics: Frequency analysis and curation of the swiss-prot database. Sci Rep. 2011;1.

[209] Mattsson N, Andreasson U, Persson S, Carrillo MC, Collins S, Chalbot S, et al. CSF biomarker variability in the Alzheimer's Association quality control program. Alzheimers Dement. 2013;9(3):251-61.

[210] Chau CH, Rixe O, McLeod H, Figg WD. Validation of analytic methods for biomarkers used in drug development. Clin Cancer Res. 2008;14(19):5967-76.

[211] Andreasson U, Perret-Liaudet A, van Doorn LJCV, Blennow K, Chiasserini D, Engelborghs S, et al. A practical guide to immunoassay method validation. Front Neurol. 2015;6.

[212] Anckaert E, Schiettecatte J, Vanbesien J, Smitz J, Velkeniers B, De Schepper J. Variability among five different commercial IGF-1 immunoassays in conditions of childhood-onset GH deficiency and GH therapy. Acta Clin Belg. 2006;61(6):335-9.

[213] Holmes EW, Garbincius J, McKenna KM. Analytical variability among methods for the measurement of 25-hydroxyvitamin D: Still adding to the noise. Am J Clin Pathol. 2013;140(4):550-60.

[214] European Medicines Agency: EMEA/CHMP/EWP/ 192217/2009 Rev. 1 Corr. 2 - Guideline on bioanalytical method validation 2011 [cited 2018 February]. Available from: http://www.ema.europa.eu/docs/en_GB/ document_library/Scientific_guideline/2011/08/WC50010 9686.pdf.

[215] Andreasson U, Perret-Liaudet A, van Waalwijk van Doorn LJ, Blennow K, Chiasserini D, Engelborghs S, et al. A practical guide to immunoassay method validation. Front Neurol. 2015;6:179.

[216] Chau CH, Rixe O, McLeod H, Figg WD. Validation of analytic methods for biomarkers used in drug development. Clin Cancer Res. 2008;14(19):5967-76.

[217] Ioannidis JP, Khoury MJ. Improving validation practices in "omics" research. Science. 2011;334(6060):1230-2.

[218] Hunter P. The reproducibility "crisis": Reaction to replication crisis should not stifle innovation. EMBO Rep. 2017;18(9):1493-6.

[219] Killoran A, Biglan KM. 8-OHdG: Its (limited) potential as a biomarker for Huntington's disease. Biomark Med. 2012;6(6):777-80

[220] Hersch SM, Gevorkian S, Marder K, Moskowitz C, Feigin $\mathrm{A}, \mathrm{Cox} \mathrm{M}$, et al. Creatine in Huntington disease is safe, tolerable, bioavailable in brain and reduces serum $8 \mathrm{OH} 2$ 'dG. Neurology. 2006;66(2):250-2.

[221] Long JD, Matson WR, Juhl AR, Leavitt BR, Paulsen JS, PREDICT-HD Investigators and Coordinators of the Huntington Study Group. $8 \mathrm{OHdG}$ as a marker for Huntington disease progression. Neurobiol Dis. 2012;46(3): 625-34.

[222] Paulsen JS, Hayden M, Stout JC, Langbehn DR, Aylward E, Ross CA, et al. Preparing for preventive clinical trials: The Predict-HD study. Arch Neurol. 2006;63(6):883-90.

[223] Borowsky B, Warner J, Leavitt BR, Tabrizi SJ, Roos RA, Durr A, et al. $8 \mathrm{OHdG}$ is not a biomarker for Huntington disease state or progression. Neurology. 2013;80(21):1934-41.

[224] Marotta F, Naito Y, Padrini F, Xuewei X, Jain S, Soresi $\mathrm{V}$, et al. Redox balance signalling in occupational stress: Modification by nutraceutical intervention. J Biol Regul Homeost Agents. 2011;25(2):221-9.
[225] Forlenza MJ, Miller GE. Increased serum levels of 8-hydroxy-2'-deoxyguanosine in clinical depression. Psychosom Med. 2006;68(1):1-7.

[226] Mizoue T, Kasai H, Kubo T, Tokunaga S. Leanness, smoking, and enhanced oxidative DNA damage. Cancer Epidemiol Biomarkers Prev. 2006;15(3):582-5.

[227] Huang HB, Lai CH, Chen GW, Lin YY, Jaakkola JJ, Liou $\mathrm{SH}$, et al. Traffic-related air pollution and DNA damage: A longitudinal study in Taiwanese traffic conductors. PloS one. 2012;7(5):e37412.

[228] Pedret A, Valls RM, Fernandez-Castillejo S, Catalan U, Romeu M, Giralt M, et al. Polyphenol-rich foods exhibit DNA antioxidative properties and protect the glutathione system in healthy subjects. Mol Nutr Food Res. 2012;56(7):1025-33.

[229] Perez DD, Strobel P, Foncea R, Diez MS, Vasquez L, Urquiaga I, et al. Wine, diet, antioxidant defenses, and oxidative damage. Ann N Y Acad Sci. 2002;957:136-45.

[230] Kaptchuk TJ. Effect of interpretive bias on research evidence. BMJ. 2003;326(7404):1453-5.

[231] Jarvinen TL, Sihvonen R, Bhandari M, Sprague S, Malmivaara A, Paavola M, et al. Blinded interpretation of study results can feasibly and effectively diminish interpretation bias. J Clin Epidemiol. 2014;67(7):769-72.

[232] Day SJ, Altman DG. Statistics Notes - Blinding in clinical trials and other studies. Brit Med J. 2000;321(7259): 504.

[233] Pal R, Alves G, Larsen JP, Moller SG. New insight into neurodegeneration: The role of proteomics. Mol Neurobiol. 2014;49(3):1181-99.

[234] Jove M, Portero-Otin M, Naudi A, Ferrer I, Pamplona R. Metabolomics of human brain aging and age-related neurodegenerative diseases. J Neuropathol Exp Neurol. 2014;73(7):640-57.

[235] Gonzalez-Couto E. Functional and systems biology approaches to Huntington's disease. Brief Funct Genomics. 2011;10(3):109-14.

[236] Jaber Z, Aouad P, Al Medawar M, Bahmad H, AbouAbbass $\mathrm{H}$, Ghandour H, et al. Role of systems biology in brain injury biomarker discovery: Neuroproteomics application. Methods Mol Biol. 2016;1462:157-74.

[237] Butti MD, Chanfreau H, Martinez D, Garcia D, Lacunza E, Abba MC. BioPlat: A software for human cancer biomarker discovery. Bioinformatics. 2014;30(12): 1782-4.

[238] Lin Y, Qian F, Shen L, Chen F, Chen J, Shen B. Computeraided biomarker discovery for precision medicine: Data resources, models and applications. Brief Bioinform. 2017; doi: 10.1093/bib/bbx158.

[239] Kotlowska A. Application of chemometric techniques in search of clinically applicable biomarkers of disease. Drug Dev Res. 2014;75(5):283-90.

[240] Feala JD, Abdulhameed MD, Yu C, Dutta B, Yu X, Schmid K, et al. Systems biology approaches for discovering biomarkers for traumatic brain injury. J Neurotrauma. 2013;30(13):1101-16.

[241] Aiche S, Sachsenberg T, Kenar E, Walzer M, Wiswedel B, Kristl T, et al. Workflows for automated downstream data analysis and visualization in large-scale computational mass spectrometry. Proteomics. 2015;15(8):1443-7.

[242] Xia J, Sinelnikov IV, Han B, Wishart DS. MetaboAnalyst 3.0-making metabolomics more meaningful. Nucleic Acids Res. 2015;43(W1):W251-7.

[243] Huan T, Forsberg EM, Rinehart D, Johnson CH, Ivanisevic J, Benton HP, et al. Systems biology guided by 
XCMS Online metabolomics. Nat Methods. 2017;14(5): 461-2.

[244] McGhee DJ, Ritchie CW, Thompson PA, Wright DE, Zajicek JP, Counsell CE. A systematic review of biomarkers for disease progression in Alzheimer's disease. PLoS One. 2014;9(2):e88854.

[245] Mattsson N, Carrillo MC, Dean RA, Devous MD Sr, Nikolcheva T, Pesini P, et al. Revolutionizing Alzheimer's disease and clinical trials through biomarkers. Alzheimers Dement (Amst). 2015;1(4):412-9.

[246] Paulsen JS, Langbehn DR, Stout JC, Aylward E, Ross CA, Nance M, et al. Detection of Huntington's disease decades before diagnosis: The Predict-HD study. J Neurol Neurosurg Psychiatry. 2008;79(8):874-80.

[247] Liebeskind DS, Kidwell CS, Sayre JW, Saver JL. Evidence of publication bias in reporting acute stroke clinical trials. Neurology. 2006;67(6):973-9.

[248] Ioannidis JP. Why most published research findings are false. PLoS Med. 2005;2(8):e124.

[249] Altman DG, Bland JM. Absence of evidence is not evidence of absence. BMJ. 1995;311(7003):485.

[250] Dwan K, Altman DG, Arnaiz JA, Bloom J, Chan AW, Cronin E, et al. Systematic review of the empirical evidence of study publication bias and outcome reporting bias. PLoS One. 2008;3(8):e3081.

[251] Littner Y, Mimouni FB, Dollberg S, Mandel D. Negative results and impact factor: A lesson from neonatology. Arch Pediatr Adolesc Med. 2005;159(11):1036-7.

[252] Caixeiro NJ, Lai K, Lee CS. Quality assessment and preservation of RNA from biobank tissue specimens: A systematic review. J Clin Pathol. 2016;69(3):260-5.

[253] Teunissen CE, Malekzadeh A, Leurs C, Bridel C, Killestein J. Body fluid biomarkers for multiple sclerosisthe long road to clinical application. Nat Rev Neurol. 2015;11(10):585-96.

[254] Teunissen C, Menge T, Altintas A, Alvarez-Cermeno JC, Bertolotto A, Berven FS, et al. Consensus definitions and application guidelines for control groups in cerebrospinal fluid biomarker studies in multiple sclerosis. Mult Scler. 2013;19(13):1802-9.

[255] Gnanapavan S, Hegen H, Khalil M, Hemmer B, Franciotta $\mathrm{D}$, Hughes $\mathrm{S}$, et al. Guidelines for uniform reporting of body fluid biomarker studies in neurologic disorders. Neurology. 2014;83(13):1210-6.

[256] Teunissen CE, Tumani H, Engelborghs S, Mollenhauer B. Biobanking of CSF: International standardization to optimize biomarker development. Clin Biochem. 2014;47(4-5):288-92.

[257] del Campo M, Mollenhauer B, Bertolotto A, Engelborghs $\mathrm{S}$, Hampel $\mathrm{H}$, Simonsen $\mathrm{AH}$, et al. Recommendations to standardize preanalytical confounding factors in Alzheimer's and Parkinson's disease cerebrospinal fluid biomarkers: An update. Biomark Med. 2012;6(4): 419-30.

[258] Vanderstichele H, Bibl M, Engelborghs S, Le Bastard N, Lewczuk P, Molinuevo JL, et al. Standardization of preanalytical aspects of cerebrospinal fluid biomarker testing for Alzheimer's disease diagnosis: A consensus paper from the Alzheimer's Biomarkers Standardization Initiative. Alzheimers Dement. 2012;8(1):65-73.

[259] Teunissen CE, Petzold A, Bennett JL, Berven FS, Brundin $\mathrm{L}$, Comabella M, et al. A consensus protocol for the standardization of cerebrospinal fluid collection and biobanking. Neurology. 2009;73(22):1914-22.
[260] International Society for Biological and Environmental Repositories (isber) 2018 [cited 2018 February]. Available from: http://www.isber.org/.

[261] VU University Medical Center Amsterdam (VUmc): Studies on effects of pre-analytical "mishandling": Options for collaboration 2018 [cited 2018 February]. Available from: http://bit.ly/CSF-stability.

[262] Campbell LD, Astrin JJ, DeSouza Y, Giri J, Patel AA, Rawley-Payne M, et al. The 2018 Revision of the ISBER Best Practices: Summary of Changes and the Editorial Team's Development Process. Biopreserv Biobank. 2018;16(1):3-6.

[263] Arneric SP, Batrla-Utermann R, Beckett L, Bittner T, Blennow K, Carter L, et al. Cerebrospinal fluid biomarkers for Alzheimer's disease: A view of the regulatory science qualification landscape from the Coalition Against Major Diseases CSF Biomarker Team. J Alzheimers Dis. 2017;55(1):19-35.

[264] Manolis E, Koch A, Deforce D, Vamvakas S. The European Medicines Agency experience with biomarker qualification. Methods Mol Biol. 2015;1243:255-72.

[265] Leptak C, Menetski JP, Wagner JA, Aubrecht J, Brady $\mathrm{L}$, Brumfield $\mathrm{M}$, et al. What evidence do we need for biomarker qualification? Sci Transl Med. 2017;9(417).

[266] European Medicines Agency: EMA/CHMP/SAWP/ 72894/2008 Rev. 3 - Qualification of novel methodologies for drug development: Guidance to applicants 2014 [cited 2018 February]. Available from: http://www. ema.europa.eu/docs/en_GB/document_library/Regulatory _and_procedural_guideline/2009/10/WC500004201.pdf.

[267] U.S. Food and Drug Administration (FDA): Letter of Support Initiative 2017 [updated 11/14/2017 cited 2018 February]. Available from: https://www.fda.gov/drugs/ developmentapprovalprocess/ucm434382.htm.

[268] Dubois B, Feldman HH, Jacova C, Hampel H, Molinuevo JL, Blennow K, et al. Advancing research diagnostic criteria for Alzheimer's disease: The IWG-2 criteria. Lancet Neurol. 2014;13(6):614-29.

[269] McKhann GM, Knopman DS, Chertkow H, Hyman BT, Jack CR Jr, Kawas CH, et al. The diagnosis of dementia due to Alzheimer's disease: Recommendations from the National Institute on Aging-Alzheimer's Association workgroups on diagnostic guidelines for Alzheimer's disease. Alzheimers Dement. 2011;7(3):263-9.

[270] Albert MS, DeKosky ST, Dickson D, Dubois B, Feldman $\mathrm{HH}$, Fox NC, et al. The diagnosis of mild cognitive impairment due to Alzheimer's disease: Recommendations from the National Institute on Aging-Alzheimer's Association workgroups on diagnostic guidelines for Alzheimer's disease. Alzheimers Dement. 2011;7(3):270-9.

[271] Sperling RA, Aisen PS, Beckett LA, Bennett DA, Craft $\mathrm{S}$, Fagan AM, et al. Toward defining the preclinical stages of Alzheimer's disease: Recommendations from the National Institute on Aging-Alzheimer's Association workgroups on diagnostic guidelines for Alzheimer's disease. Alzheimers Dement. 2011;7(3):280-92.

[272] Morris JC, Blennow K, Froelich L, Nordberg A, Soininen $\mathrm{H}$, Waldemar $\mathrm{G}$, et al. Harmonized diagnostic criteria for Alzheimer's disease: Recommendations. J Intern Med. 2014;275(3):204-13.

[273] Nies MK, Ivy DD, Everett AD. The untapped potential of proteomic analysis in pediatric pulmonary hypertension. Proteomics Clin Appl. 2014;8(11-12):862-74.

[274] Olsson MG, Davidsson S, Muhammad ZD, Lahiri N, Tabrizi SJ, Akerstrom B, et al. Increased levels of 
hemoglobin and alpha1-microglobulin in Huntington's disease. Front Biosci (Elite Ed). 2012;4:950-7.

[275] Belendiuk K, Belendiuk GW, Freedman DX. Blood monoamine metabolism in Huntington's disease. Arch Gen Psychiatry. 1980;37(3):325-32.

[276] Huang YC, Wu YR, Tseng MY, Chen YC, Hsieh SY, Chen CM. Increased prothrombin, apolipoprotein A-IV, and haptoglobin in the cerebrospinal fluid of patients with Huntington's disease. PLoS One. 2011;6(1):e15809.

[277] Markianos M, Panas M, Kalfakis N, Vassilopoulos D. Low plasma total cholesterol in patients with Huntington's disease and first-degree relatives. Mol Genet Metab. 2008;93(3):341-6.

[278] Nielsen SM, Vinther-Jensen T, Nielsen JE, Norremolle A, Hasholt L, Hjermind LE, et al. Liver function in Huntington's disease assessed by blood biochemical analyses in a clinical setting. J Neurol Sci. 2016;362:326-32.

[279] Chang KH, Cheng ML, Tang HY, Huang CY, Wu YR, Chen CM. Alternations of metabolic profile and kynurenine metabolism in the plasma of Parkinson's disease. Mol Neurobiol. 2018; doi: 10.1007/s12035-017-0845-3.

[280] Chen CM, Lin YS, Wu YR, Chen P, Tsai FJ, Yang CL, et al. High protein diet and Huntington's disease. PLoS One. 2015;10(5):e0127654.

[281] Chiang MC, Chen HM, Lee YH, Chang HH, Wu YC, Soong BW, et al. Dysregulation of C/EBPalpha by mutant Huntingtin causes the urea cycle deficiency in Huntington's disease. Hum Mol Genet. 2007;16(5):483-98.

[282] Oepen G, Cramer H, Bernasconi R, Martin P. Huntington's disease - imbalance of free amino acids in the cerebrospinal fluid of patients and offspring at-risk. Arch Psychiatr Nervenkr (1970). 1982;231(2):131-40.

[283] Bohlen P, Tell G, Schechter PJ, Koch-Weser J, Agid Y, Coquillat G, et al. Cerebrospinal fluid homocarnosine in Huntington's disease. Life Sci. 1980;26(13):1009-12.

[284] Markianos M, Panas M, Kalfakis N, Vassilopoulos D. Plasma homovanillic acid and prolactin in Huntington's disease. Neurochem Res. 2009;34(5):917-22.

[285] Cunha L, Oliveira CR, Diniz M, Amaral R, Concalves AF, Pio-Abreu J. Homovanilic acid in Huntington's disease and Sydenham's chorea. J Neurol Neurosurg Psychiatry. 1981;44(3):258-61.

[286] Garcia Ruiz PJ, Mena MA, Sanchez Bernardos V, Diaz Neira W, Gimenez Roldan S, Benitez J, et al. Cerebrospinal fluid homovanillic acid is reduced in untreated Huntington's disease. Clin Neuropharmacol. 1995; 18(1):58-63.

[287] Garrett MC, Soares-da-Silva P. Increased cerebrospinal fluid dopamine and 3,4-dihydroxyphenylacetic acid levels in Huntington's disease: Evidence for an overactive dopaminergic brain transmission. J Neurochem. 1992;58(1):101-6.

[288] Reilmann R, Rolf LH, Lange HW. Huntington's disease: The neuroexcitotoxin aspartate is increased in platelets and decreased in plasma. J Neurol Sci. 1994;127(1): 48-53.

[289] Koroshetz WJ, Jenkins BG, Rosen BR, Beal MF. Energy metabolism defects in Huntington's disease and effects of coenzyme Q10. Ann Neurol. 1997;41(2):160-5.

[290] Shirbin CA, Chua P, Churchyard A, Hannan AJ, Lowndes $\mathrm{G}$, Stout JC. The relationship between cortisol and verbal memory in the early stages of Huntington's disease. J Neurol. 2013;260(3):891-902.

[291] Kremer HP, Roos RA, Frolich M, Radder JK, Nieuwenhuijzen Kruseman AC, Van der Velde A, et al. Endocrine functions in Huntington's disease. A two-and-a-half years follow-up study. J Neurol Sci. 1989;90(3):335-44.

[292] Durso R, Tamminga CA, Denaro A, Ruggeri S, Chase TN. Plasma growth hormone and prolactin response to dopaminergic GABAmimetic and cholinergic stimulation in Huntington's disease. Neurology. 1983;33(9): 1229-32.

[293] Podolsky S, Leopold NA. Abnormal glucose tolerance and arginine tolerance tests in Huntington's disease. Gerontology. 1977;23(1):55-63.

[294] Leopold NA, Podolsky S. Exaggerated growth hormone response to arginine infusion in Huntington's disease. J Clin Endocrinol Metab. 1975;41(1):160-3.

[295] Saleh N, Moutereau S, Azulay JP, Verny C, Simonin C, Tranchant $\mathrm{C}$, et al. High insulinlike growth factor $\mathrm{I}$ is associated with cognitive decline in Huntington disease. Neurology. 2010;75(1):57-63.

[296] Salem L, Saleh N, Desamericq G, Youssov K, Dolbeau G, Cleret $\mathrm{L}$, et al. Insulin-like growth factor-1 but not insulin predicts cognitive decline in Huntington's disease. PLoS One. 2016;11(9):e0162890.

[297] Aziz NA, Pijl H, Frolich M, van der Graaf AW, Roelfsema F, Roos RA. Leptin secretion rate increases with higher CAG repeat number in Huntington's disease patients. Clin Endocrinol (Oxf). 2010;73(2):206-11.

[298] Vinther-Jensen T, Simonsen AH, Budtz-Jorgensen E, Hjermind LE, Nielsen JE. Ubiquitin: A potential cerebrospinal fluid progression marker in Huntington's disease. Eur J Neurol. 2015;22(10):1378-84.

[299] Bonilla E, Estevez J, Suarez H, Morales LM, Chacin de Bonilla L, Villalobos R, et al. Serum ferritin deficiency in Huntington's disease patients. Neurosci Lett. 1991;129(1):22-4.

[300] Morrison PJ, Nevin NC. Serum iron, total iron binding capacity and ferritin in early Huntington disease patients. Ir J Med Sci. 1994;163(5):236-7.

[301] Heyes MP, Saito K, Crowley JS, Davis LE, Demitrack MA, Der M, et al. Quinolinic acid and kynurenine pathway metabolism in inflammatory and non-inflammatory neurological disease. Brain. 1992;115 (Pt 5):1249-73.

[302] Beal MF, Matson WR, Swartz KJ, Gamache PH, Bird ED. Kynurenine pathway measurements in Huntington's disease striatum: Evidence for reduced formation of kynurenic acid. J Neurochem. 1990;55(4):1327-39.

[303] Manyam NV, Hare TA, Katz L, Glaeser BS. Huntington's disease. Cerebrospinal fluid GABA levels in at-risk individuals. Arch Neurol. 1978;35(11):728-30.

[304] Manyam BV, Tremblay RD. Free and conjugated GABA in human cerebrospinal fluid: Effect of degenerative neurologic diseases and isoniazid. Brain Res. 1984;307(12):217-23.

[305] Enna SJ, Stern LZ, Wastek GJ, Yamamura HI. Cerebrospinal fluid gamma-aminobutyric acid variations in neurological disorders. Arch Neurol. 1977;34(11): 683-5.

[306] Nicoli F, Vion-Dury J, Maloteaux JM, Delwaide C, Confort-Gouny S, Sciaky M, et al. CSF and serum metabolic profile of patients with Huntington's chorea: A study by high resolution proton NMR spectroscopy and HPLC. Neurosci Lett. 1993;154(1-2):47-51.

[307] Achar VS, Welch KM, Chabi E, Bartosh K, Meyer JS. Cerebrospinal fluid gamma-aminobutyric acid in neurologic disease. Neurology. 1976;26(8):777-80.

[308] Tasset I, Sanchez-Lopez F, Aguera E, Fernandez-Bolanos R, Sanchez FM, Cruz-Guerrero A, et al. NGF and 
nitrosative stress in patients with Huntington's disease. J Neurol Sci. 2012;315(1-2):133-6.

[309] Lorigados L, Soderstrom S, Ebendal T. Two-site enzyme immunoassay for beta NGF applied to human patient sera. J Neurosci Res. 1992;32(3):329-39.

[310] Toczek M, Zielonka D, Zukowska P, Marcinkowski JT, Slominska E, Isalan $\mathrm{M}$, et al. An impaired metabolism of nucleotides underpins a novel mechanism of cardiac remodeling leading to Huntington's disease related cardiomyopathy. Biochim Biophys Acta. 2016;1862(11):2147-57.

[311] Pettegrew JW, Glonek T, Stewart RM. Phosphorus-31 magnetic resonance studies on blood in Huntington's disease. Trans Am Neurol Assoc. 1979;104:233-5.

[312] Markianos M, Panas M, Kalfakis N, Vassilopoulos D. Plasma testosterone in male patients with Huntington's disease: Relations to severity of illness and dementia. Ann Neurol. 2005;57(4):520-5.

[313] Boesgaard TW, Nielsen TT, Josefsen K, Hansen T, Jorgensen T, Pedersen O, et al. Huntington's disease does not appear to increase the risk of diabetes mellitus. J Neuroendocrinol. 2009;21(9):770-6.

[314] Perry TL, Hansen S. What excitotoxin kills striatal neurons in Huntington's disease? Clues from neurochemical studies. Neurology. 1990;40(1):20-4.

[315] Aziz NA, Pijl H, Frolich M, Roelfsema F, Roos RA. Altered thyrotropic and lactotropic axes regulation in Huntington's disease. Clin Endocrinol (Oxf). 2010;73(4):540-5

[316] Auinger P, Kieburtz K, McDermott MP. The relationship between uric acid levels and Huntington's disease progression. Mov Disord. 2010;25(2):224-8.
[317] Davis KL, Hollister LE, Livesey J, Berger PA. Cerebrospinal fluid acetylcholinesterase in neuropsychiatric disorders. Psychopharmacology (Berl). 1979;63(2): 155-9.

[318] Manyam BV, Giacobini E, Colliver JA. Cerebrospinal fluid acetylcholinesterase and choline measurements in Huntington's disease. J Neurol. 1990;237(5):281-4.

[319] Baumann CR, Hersberger M, Bassetti CL. Hypocretin1 (orexin A) levels are normal in Huntington's disease. J Neurol. 2006;253(9):1232-3.

[320] Bjorkqvist M, Petersen A, Nielsen J, Ecker D, Mulder H, Hayden MR, et al. Cerebrospinal fluid levels of orexinA are not a clinically useful biomarker for Huntington disease. Clin Genet. 2006;70(1):78-9.

[321] Gaus SE, Lin L, Mignot E. CSF hypocretin levels are normal in Huntington's disease patients. Sleep. 2005;28(12):1607-8.

[322] Aziz A, Fronczek R, Maat-Schieman M, Unmehopa $\mathrm{U}$, Roelandse F, Overeem S, et al. Hypocretin and melanin-concentrating hormone in patients with Huntington disease. Brain Pathol. 2008;18(4):474-83.

[323] Heyes MP, Swartz KJ, Markey SP, Beal MF. Regional brain and cerebrospinal fluid quinolinic acid concentrations in Huntington's disease. Neurosci Lett. 1991;122(2):265-9.

[324] Schwarcz R, Tamminga CA, Kurlan R, Shoulson I. Cerebrospinal fluid levels of quinolinic acid in Huntington's disease and schizophrenia. Ann Neurol. 1988;24(4): 580-2. 